\title{
Frit Inlet Field-flow fractionation techniques for the characterization of polyion complex self-assemblies
}

Ugo Tilla,b, Mireille Gaucher ${ }^{\mathrm{b}}$, Baptiste Amouroux ${ }^{\mathrm{a}}$, Stéphane Gineste ${ }^{\mathrm{a}}$, Barbara Lonetti ${ }^{\mathrm{a}}$, Jean-Daniel Martya, Christophe Mingotaud ${ }^{a}$, Carmen R.M. Bria ${ }^{c}$, S. Kim Ratanathanawongs Williams ${ }^{\mathrm{c}}$, Frédéric Violleau ${ }^{\mathrm{d}, *}$, Anne-Françoise Mingotaud ${ }^{\mathrm{a}, *}$

Keywords : Flow Field-Flow Fractionation, Frit Inlet Flow Field-Flow Fractionation, polyion complex micelles, polymers, self-assembly

\begin{abstract}
Polymer self-assemblies joining oppositely charged chains, known as polyion complexes (PICs), have been formed using poly(ethyleneoxide - b - acrylic acid) / poly(L-lysine), poly(ethyleneoxide-b-acrylic acid)/dendrigraft poly(L-lysine) and poly[(3-acrylamidopropyl) trimethylammonium chloride - b - N - isopropyl acrylamide]/poly(acrylic acid). The selfassemblies have been first characterized in batch by Dynamic Light Scattering. In a second step, their analysis by Flow Field-Flow Fractionation techniques (FIFFF) was examined. They
\end{abstract}


were shown to be very sensitive to shearing, especially during the focus step of the fractionation, and this led to an incompatibility with asymmetrical FlFFF. On the other hand, Frit Inlet FlFFF proved to be very efficient to observe them, either in its symmetrical (FIFIFFF) or asymmetrical version (FI-AsFlFFF). Conditions of elution were found to optimize the sample recovery in pure water. Spherical self-assemblies were detected, with a size range between 70 and $400 \mathrm{~nm}$ depending on the polymers. Compared to batch DLS, FI-AsFlFFF clearly showed the presence of several populations in some cases. The influence of salt on poly(ethyleneoxide-b-acrylic acid) (PEO-PAA) 6000-3000 / dendrigraft poly(L-lysine) (DGL 3) was also assessed in parallel in batch DLS and FI-AsF1FFF. Batch DLS revealed a first process of swelling of the self-assembly for low concentrations up to $0.8 \mathrm{M}$ followed by the dissociation. FI-AsFlFFF furthermore indicated a possible ejection of DGL3 from the PIC assembly for concentrations as low as $0.2 \mathrm{M}$, which could not be observed in batch DLS.

\section{Introduction}

Thanks to the tremendous evolution of polymer engineering over the last thirty years, a large variety of copolymers is now available. This has led to the explosion of polymers able to form different self-assembled nano-objects, using either amphiphilic or double hydrophilic block copolymers. The latter may form associations if one of the blocks is a polyelectrolyte, either weak or strong. In such a case, in the presence of another (block co)polymer of the opposite charge, electrostatic interactions will prevail and expulsion of existing small counterions will be favored for entropic reasons, leading to formation of self-assemblies. If the assembly only involves homopolyelectrolytes, it is named interpolyelectrolyte complex (IPEC) [1]. This leads to macroscopic precipitation from the solution for the stoichiometric ratio $1 / 1$ between the cationic and anionic groups. If at least one of the involved polymers is a copolymer exhibiting a neutral block, the assembly is then called "polyion complex micelle" (PICs) or "block ionomer complex" and conditions can be found to maintain its solubility[2-5]. A recent review summarized all the different morphologies described in the literature [1]. Neutral hydrophilic blocks used for PICs include poly(ethyleneglycol), hydrophilic polyacrylates, polyacrylamides, polyoxazolines or poly(vinylpyrrolidone). Polyelectrolyte blocks used have been charged polypeptides, charged polyacrylates or DNAs. Compared to nano-objects formed from amphiphilic block copolymers, PICs exhibit similarities in terms of possible size range (typically from 20 to a few hundred nanometers) and techniques for their characterization (classically Dynamic or Static Light Scattering (DLS or SLS) and Transmission Electron Microscopy (TEM)). Marked differences however exist, the strongest one being the sensitivity to salt. Unlike amphiphilic block copolymers assemblies, PICs have been shown to present a very low stability with increasing salt concentration, owing to the displacement of the electrostatic interactions[6, 7]. They have 
been observed, by light scattering, to dissociate for salt concentrations typically higher than $0.5 \mathrm{M}$. In the case of weak polyelectrolytes, they are also sensitive to $\mathrm{pH}$ and the assembly is only observed for a given range of $\mathrm{pH}[8]$. This sensitivity of PICs to both ionic strength and $\mathrm{pH}$ has led people to develop stabilization strategies by crosslinking [5, 9-12]. PICs are particularly assessed as drug vectors, for instance for photodynamic therapy. The asset of this strategy is that it enables a high encapsulating ratio of the drug, since it is one of the essential blocks of the assembly, acting as a drug vector[10, 13-16].

All the nano-objects used for nanomedicine, either formed from amphiphilic or double hydrophilic block copolymers necessitate a characterization that should be as thorough as possible. For this, two techniques are routinely used, namely DLS and TEM. DLS, although routinely used, should be taken with great care[17, 18], especially for nano-objects exhibiting a size polydispersity, which is in most cases for polymeric self-assemblies. Furthermore, working directly on a whole solution of nano-objects, DLS can only provide an average value of their size.

On the other hand, TEM enables an individual visualization of the nano-objects, in their dried state. The advantage is then to directly see the objects and their shape, which is not possible with DLS. The drawback however is the limited objects number which is analyzed, since only a part of the solution is imaged. Furthermore, this implies drying of the solution, possibly leading to re-arrangement of the self-assemblies.

In order to improve the characterization of nano-objects, other techniques are also used, such as static light scattering (SLS), neutron (SANS) or X-ray (SAXS) scattering, or cryo-TEM. SANS and SAXS imply correct mathematical fitting of the experimental curves and a difficult accessibility to the instruments[18]. Furthermore, for all batch techniques SLS, SANS or SAXS, the solution being analyzed in its whole, the results are highly dependent on the possible presence of different families of nano-objects. Finally, cryo-TEM enables a direct visualization of the objects without the need for drying them. This powerful method however is sometimes difficult to perform in order to obtain clear glassy ice, and a large dispersity in size of the nano-objects may be complex to analyze owing to different positioning of the nano-objects on the grid during the fast freezing process (linked to the thickness of the ice layer, that might be close to the size of the nano-objects themselves).

This quick overview of the analysis techniques for nano-objects points out the great difficulty to have a thorough characterization, especially because of the polydispersity of the samples. In order to use these techniques while limiting the influence of polydispersity, their combination with fractionation techniques is a choice approach. Indeed, regular chromatography such as Size Exclusion Chromatography should be avoided for selfassemblies, since the presence of the stationary phase together with high shearing during elution might lead to modification of the assemblies. For this reason, Field-Flow Fractionation (FFF) techniques and mainly Flow FFF have been increasingly assessed as separation 
methods for nanoparticles and are associated to subsequent characterization by RI, multiangle light scattering (MALS), UV-visible or DLS detection[19]. In a recent review, Roda et $a l$. explained that the application of current nanotechnologies suffered from the present difficulty of developing well defined nanoparticles, or efficient techniques to characterize the existing ones. FFF was developed more than 30 years ago and the technical progresses have enabled its use in various domains such as environmental, food, polymer and pharmaceutical industry analyses [20-29]. Samples injected into FIFFF systems require a separate relaxation process prior to the separation. This process is essential to FFF as sample components are 'relaxed' into different equilibrium positions and thus different velocity streamlines of the parabolic flow profile. For a conventional symmetrical Flow FFF channel, the axial flow is stopped for a certain period to allow this relaxation process to take place. For an Asymmetrical Flow FFF, sample relaxation is normally achieved by using a focusing process. While the stop-flow and focusing processes are essential in each flow FFF sub-technique, they may lead to baseline fluctuations and to undesirable particle interactions with the channel wall[30, 31].

The unwanted effects of stop-flow and focusing processes can be avoided by using hydrodynamic relaxation methods that were introduced by implementing a split inlet or a frit inlet $[31,32]$ in a symmetrical flow FFF channel. In the same way, Moon and colleagues. described extensively[33-39] a frit inlet injection technique applied to an asymmetrical flow FFF channel to allow a stop-less sample injection. With the application of a hydrodynamic relaxation technique using a frit inlet in asymmetrical flow FFF, the focusing process can be completely avoided. This technique has shown its efficiency for fractionation of different macromolecules and particles like lipoprotein particles[40], carbon nanotubes[41], sodium hyaluronate[42-44] and ultrahigh-molecular weight cationic polyacrylamide[45] reducing risk of adsorption on the FFF membrane and/or sample aggregation.

In this work, we demonstrate that Asymmetrical Flow Field-Flow Fractionation (AsFlFFF) is a powerful method to characterize polymeric micelles and vesicles[46-49], explicitly showing the relative ratio of different populations of self-assemblies in a sample, where batch DLS only showed the largest populations. In order to further diversify the application domain of FFF, we assessed the characterization of different PICs, based either on commercial or home-made polymers. Indeed, to the best of our knowledge, only a few studies have described the use of FFF techniques for the characterization of charged polymers assemblies. Two of them studied polyelectrolyte complexes using As-FlFFF[50, 51] involving two oppositely charged homopolymers. Another described As-FlFFF analysis of poly(ethylene oxide-b-sodium methacrylate) / poly(methacryloxyethyl trimethylammonium chloride) self-assemblies which are the most similar to the PICs of our work[52]. This unique literature example on PICs characterization by FFF showed that further studies are needed in order to assess the usefulness of FFF techniques for such self-assemblies. 


\section{Materials and methods}

\subsection{Chemicals}

Poly(acrylic acid) (PAA) and Poly(lysine) PLys (15000-3000 g.mol-1) were purchased from Aldrich, poly(ethyleneoxide-b-acrylic acid) (PEO-PAA) from Polymer Source Inc. (Dorval Montréal, Canada), dendrigraft polylysine (DGL) from Colcom (Montpellier, France). Poly[(3-acrylamidopropyl) trimethylammonium chloride - b - N - isopropyl acrylamide] (PAPTAC-PNIPAM) was kindly provided by M. Destarac (IMRCP laboratory) and was synthesized by RAFT polymerization[53].

\subsection{Formation of PICs}

PEO-PAA/ DGL3 PICs were prepared by mixing DGL3 (5 mg.mL $\left.{ }^{-1}\right)$ stock solution at $\mathrm{pH} 7$ with adequate amounts of PEO-PAA $\left(1 \mathrm{mg} \cdot \mathrm{mL}^{-1}\right)$ stock solution at $\mathrm{pH} 7$ in order to have the same concentration of carboxylic acids and amino groups. These solutions were further diluted with water in order to achieve a final DGL3 concentration of $0.1 \mathrm{wt} \%$.

In a similar way, PEO-PAA/PLys solutions were obtained by addition of $85 \mu \mathrm{L}$ of PEO-PAA 5-38 in phosphate buffer $\mathrm{pH} 7.4\left(2 \mathrm{mg} \cdot \mathrm{mL}^{-1}\right)$ to $3 \mathrm{~mL} \mathrm{LysHBr}$ in phosphate buffer $\mathrm{pH} 7.4$ (0.16 $\left.\mathrm{mg} \cdot \mathrm{mL}^{-1}\right)$.

PAPTAC-PNIPAM and PAA (adjusted $\mathrm{pH}$ at 5.5 by adding $\mathrm{NaOH}$ solution) were separately dissolved in water, giving clear colorless solutions. PAPTAC-PNiPAM / PAA PICs were prepared by mixing appropriate amounts of each polymer, at a desired stoichiometric ratio, and water to obtain the right concentration. First a volume of PAPTAC-PNIPAM solution and water were mixed, and then the appropriate amount of PAANa solution was added.

PEO-PAA/DGL3 PICs at different $\mathrm{NaCl}$ concentrations were obtained by mixing, in the following order, DGL3 mother solution $(0.5 \mathrm{wt} \%)$ at $\mathrm{pH}$ 6.7, water, PEO-PAA stock solution $(0.5 \mathrm{wt} \%)$ at $\mathrm{pH} 7$ and $\mathrm{NaCl}$ stock solution (6M). PEO-PAA stock solution was added in order to have a ratio of 1 between carboxylic acid and amino groups. Adequate amounts of $\mathrm{NaCl}$ stock solution were added in order to have a final salt concentration of $0.2,0.8,1$ and $2 \mathrm{M}$. Pure water was added in order to get a final DGL3 concentration of $0.1 \mathrm{wt} \%$.

\subsection{Dialysis follow-up}


Solutions of PEO-PAA 6-3 / DGL3 PIC in 0.2 and 2.0 M NaCl solutions were formed by mixing varying volumes of polymer solutions in water to concentrated $4 \mathrm{M} \mathrm{NaCl}$ solution. $3 \mathrm{~mL}$ of these solutions were introduced in dialysis flasks (GE Healthcare Bio-Sciences membranes with a MWCO of 1000 g.mol-1) and dialyzed against $800 \mathrm{~mL}$ of milliQ water. The dialysis process was interrupted at specific times in order to perform DLS analysis.

\section{$2.4 D L S$}

DLS was carried out at $25^{\circ} \mathrm{C}$ on a Malvern Zetasizer NanoZS equipped with a He-Ne laser $(\lambda=633 \mathrm{~nm})$. Solutions were analyzed as synthesized without filtration to ensure that large populations were not discarded from analysis. Polydispersity indices (PDI) were obtained from the correlation function by using a cumulant analysis. The correlation function was analyzed via the general-purpose non-negative least squares (NNLS) method to obtain the intensity-weighted distribution of diffusion coefficients (D) of the solutes. This distribution can be converted, using Mie theory, to a number-weighted distribution describing the relative proportion of multiple components in the sample based on their number rather than based on their scattering. The average apparent hydrodynamic diameters, noted as 'DLS Size $_{\text {Int }}$ ' or 'DLS Size Number', were determined using the Stokes-Einstein equation from intensity-weighted and number-weighted distributions, respectively. Unless stated, the term size refers to diameters. Each solution was analyzed 3-5 times depending on the observed correlogram. The typical accuracy for these measurements was $10-20 \%$ for systems exhibiting a polydispersity index (PDI) lower than 0.4. This PDI is defined as the ratio between the second moment of the distribution divided by the square of the mean value of the decay rate. The values presented in the tables are not mean values, because this is not relevant for DLS analysis of multi-population samples. Indeed, in such case, the DLS software will exhibit a larger inaccuracy for the least present population. Thus, the results presented in the tables are those obtained for a typical result for each analysis.

The Malvern DLS data were further analyzed by a custom-made program named STORMS in order to obtain a more precise characterization of the solutions. This program has been designed with Matlab ${ }^{\circledR}$ and enables the fitting of DLS correlograms using different sets of parameters, corresponding to all hypotheses that have to be made for fitting the correlograms. Indeed, going from correlograms to size results implies three levels of hypotheses: the first consists of the transformation of autocorrelation data to diffusion coefficient, the second extracts the size of the scattering object from diffusion coefficient depending on its geometry, and finally uses a model enabling the transformation of the intensity-relative population to a number-relative equivalent. For each step, STORMS provided the choice of different parameters. For the nano-objects presented here, the protocol used a non negative least squares (NNLS) fitting, assumed a spherical shape for all objects, 
and the chosen scattering model was that corresponding to spheres (Rayleigh or Mie's model depending on the size). The range of decay rates and the regularization parameter were systematically modified to check the consistency of the results (supplementary information). Unless stated, this treatment provided residuals lower than $5 \times 10^{-3}$ for all analyses. The estimated PDI in STORMS is often larger than that calculated by the MALVERN software since all the experimental points are selected and the second order equation is used in STORMS instead of the third one for Malvern.

\subsection{Frit Inlet Symmetrical FlFFF (FI-FlFFF)}

A Frit-inlet Frit-outlet Symmetrical Flow Field-Flow Fractionation channel (FFFractionation, Salt Lake City, UT) was used and eluent was supplied by three pumps (Waters 510 HPLC and two Waters 590 HPLC) as depicted in figure 1 . The accumulation wall was a $1 \mathrm{kDa}$ cut-off regenerated cellulose ultrafiltration membrane (Postnova Analytics, Landsberg am Lech, Germany). The sample injection was triggered manually with a 6-way valve into the Frit-inlet SyFlFFF channel. A pressure controller (custom made) was installed after the detectors. The eluting sample components were detected with a Water 410 Refractometer (Waters US) and a UV detector (Waters 486 Tunable Absorbance Detector (401nm)). An aqueous 0.02 wt \% sodium azide solution was filtered (vacuum filtration system with $0.1 \mathrm{~mm}$ pore size Gelman filters) before use as eluent. The spacer type was $250 \mathrm{~S}$ which corresponded to $\sim 250 \mu \mathrm{m}$ thickness. Samples were injected at a $0.5 \mathrm{wt} \%$ concentration. The elution program used for the cross flow rate $V_{\text {cross }}$ was $0.6 \mathrm{~mL} \cdot \mathrm{min}^{-1}$ during all the tests while $\mathrm{V}_{\mathrm{i}}$ and $\mathrm{V}_{\mathrm{f}}$ were subjected to variation from 0.4 to 1.2 and from 0 to $8 \mathrm{~mL} \cdot \mathrm{min}^{-1}$, respectively.

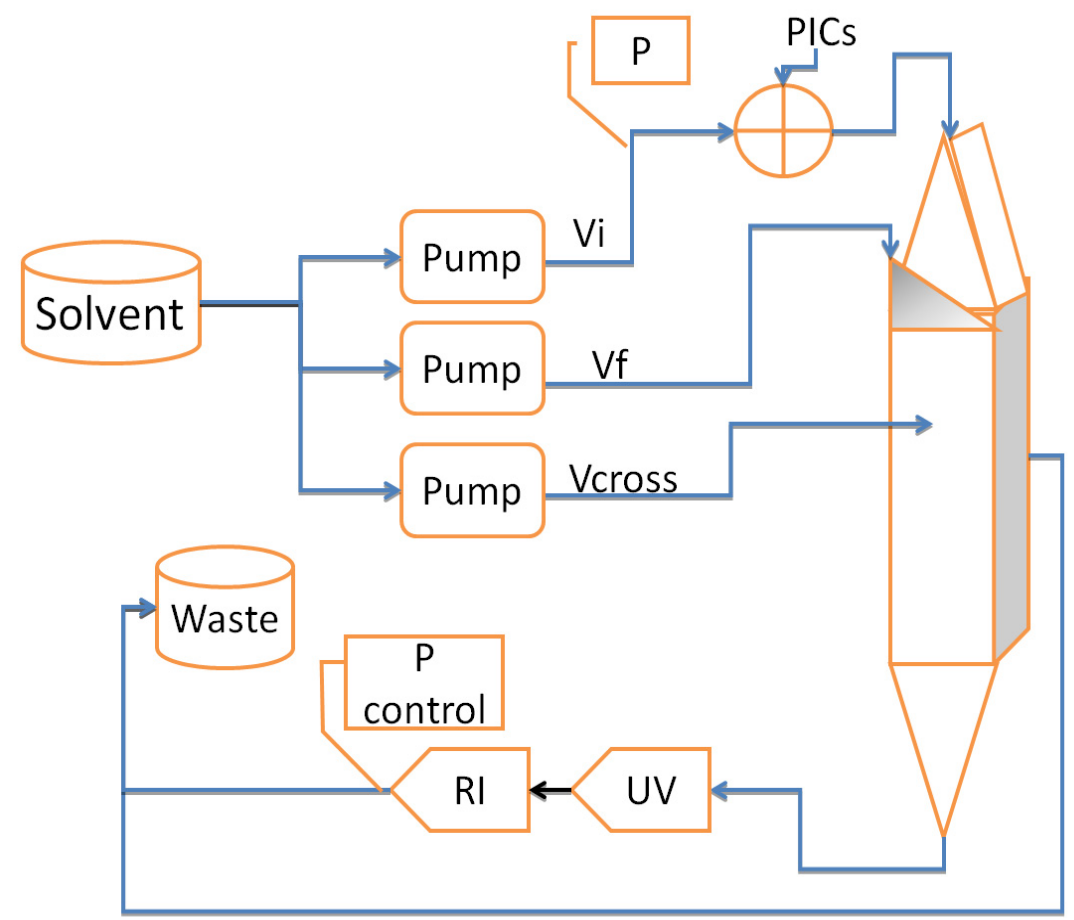


Figure 1. Experimental set-up for Symmetrical FFF

\subsection{Frit Inlet Asymmetrical Flow Field-Flow Fractionation (FI-AsFlFFF)}

A Frit-inlet Asymmetrical Flow Field-Flow Fractionation channel was linked to an Eclipse 3 system (Wyatt Technology Europe, Dernbach, Germany, figure 2). The accumulation wall was a $1 \mathrm{kDa}$ cut-off regenerated cellulose ultrafiltration membrane (ConSenxuS, Ober-Hilbersheim, Germany). An Agilent 1100 Series Isocratic Pump (Agilent Technologies, Waldbronn, Germany) with an in-line vacuum degasser and an Agilent 1100 Autosampler delivered the carrier flow and handled sample injection into the Frit inlet AsFlFFF channel. A $0.1 \mathrm{~mm}$ in-line filter (VVLP, Millipore, Germany) was installed between the pump and the FFF channel. An aqueous $0.02 \%$ sodium azide solution was filtered (vacuum filtration system using $0.1 \mathrm{~mm}$ Gelman filters) before use as eluent. The spacer type was $250 \mathrm{~S}$ or $350 \mathrm{~S}$ ( $250 \mu \mathrm{m}$ or $350 \mu \mathrm{m}$, respectively). Samples were injected either at a 0.5 or $0.1 \mathrm{wt} \%$ concentration. The elution program used for injection flow $\mathrm{V}_{\mathrm{i}}$ of $0.2 \mathrm{~mL} \cdot \mathrm{min}^{-1}$ and for detector flow $\mathrm{V}_{\text {out }}$ of $1 \mathrm{~mL} \cdot \mathrm{min}^{-1}$ for cross flow $\mathrm{V}_{\mathrm{x}}$ was $0.5 \mathrm{~mL} \cdot \mathrm{min}^{-1}$ for $2 \mathrm{~min}, 2 \mathrm{~mL} \cdot \mathrm{min}^{-1}$ for $38 \mathrm{~min}$, decreased to $0.5 \mathrm{~mL} \cdot \mathrm{min}^{-1}$ in $10 \mathrm{~min}$ followed by $0.5 \mathrm{~mL} \cdot \mathrm{min}^{-1}$ for $40 \mathrm{~min}$. The eluted sample components were detected with Multi-Angle Light Scattering (MALS) DAWN Heleos II (Wyatt Technology, Santa Barbara, CA, US) equipped with a DLS (DLS) at $99^{\circ}$ and an OptilabRex Refractometer (Wyatt Technology, Santa Barbara, CA, US) detectors. The MALS detector was normalized with bovine serum albumin (BSA). Calibration of scattering intensity was performed with HPLC-grade filtered toluene.

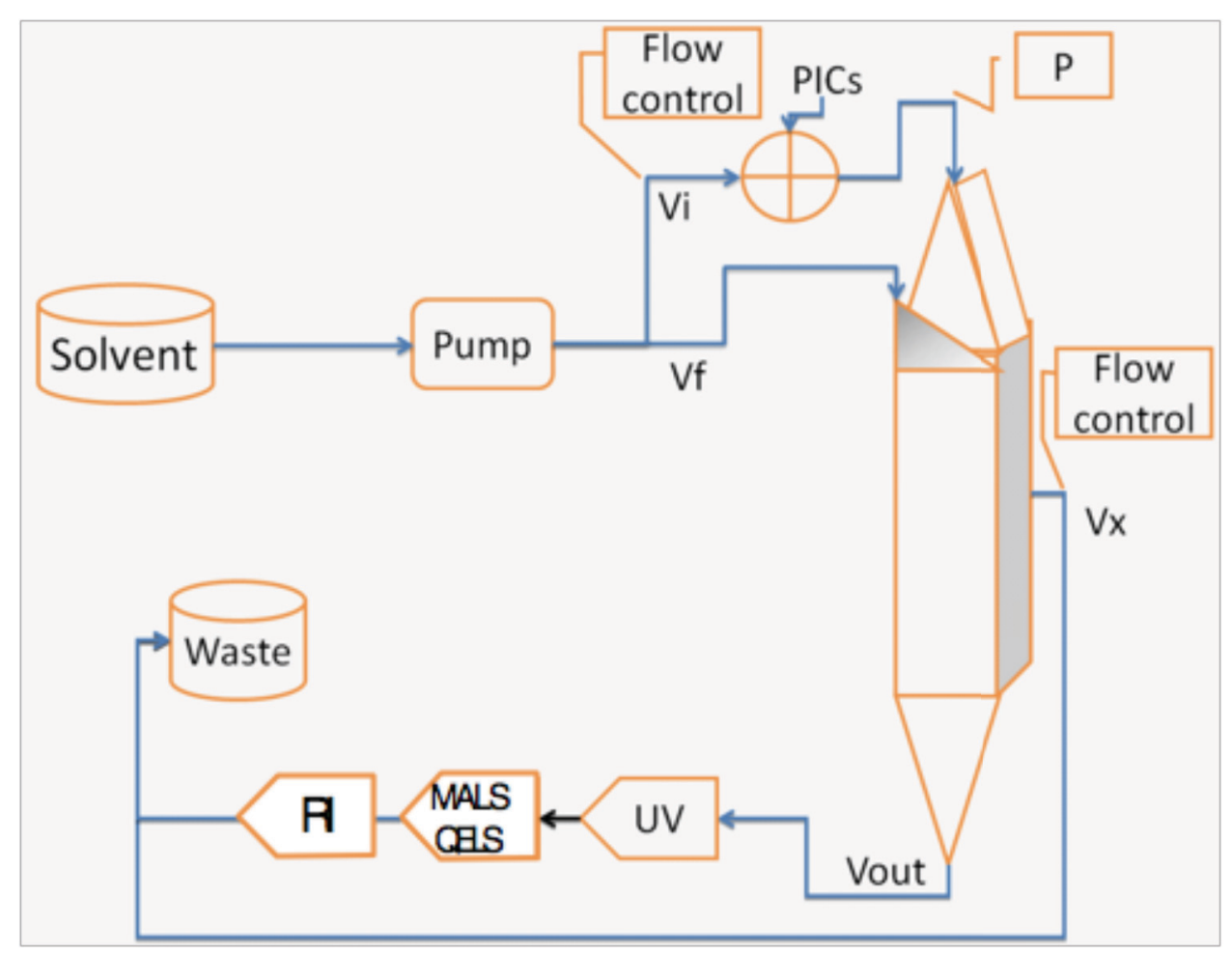


Figure 2. Experimental set-up for Asymmetrical FFF

\section{Results and discussion}

\subsection{Formation of PICs}

Different polymers were used to form the self-assemblies (figure 3 and table 1), having acidic (PEO-PAA and PAA) or amino or ammonium groups (PLys, DGL, PAPTAC-PNIPAM). DGL is a dendrigraft form of polylysine. These polymers were chosen in order to have a variety of molar masses and architectures. PICs were formed by direct mixing of two solutions of the constituents at appropriate $\mathrm{pH}$. The studied pairs were PEO-PAA/DGL, PEO-PAA/PLys and PAPTAC-PNIPAM/PAA.

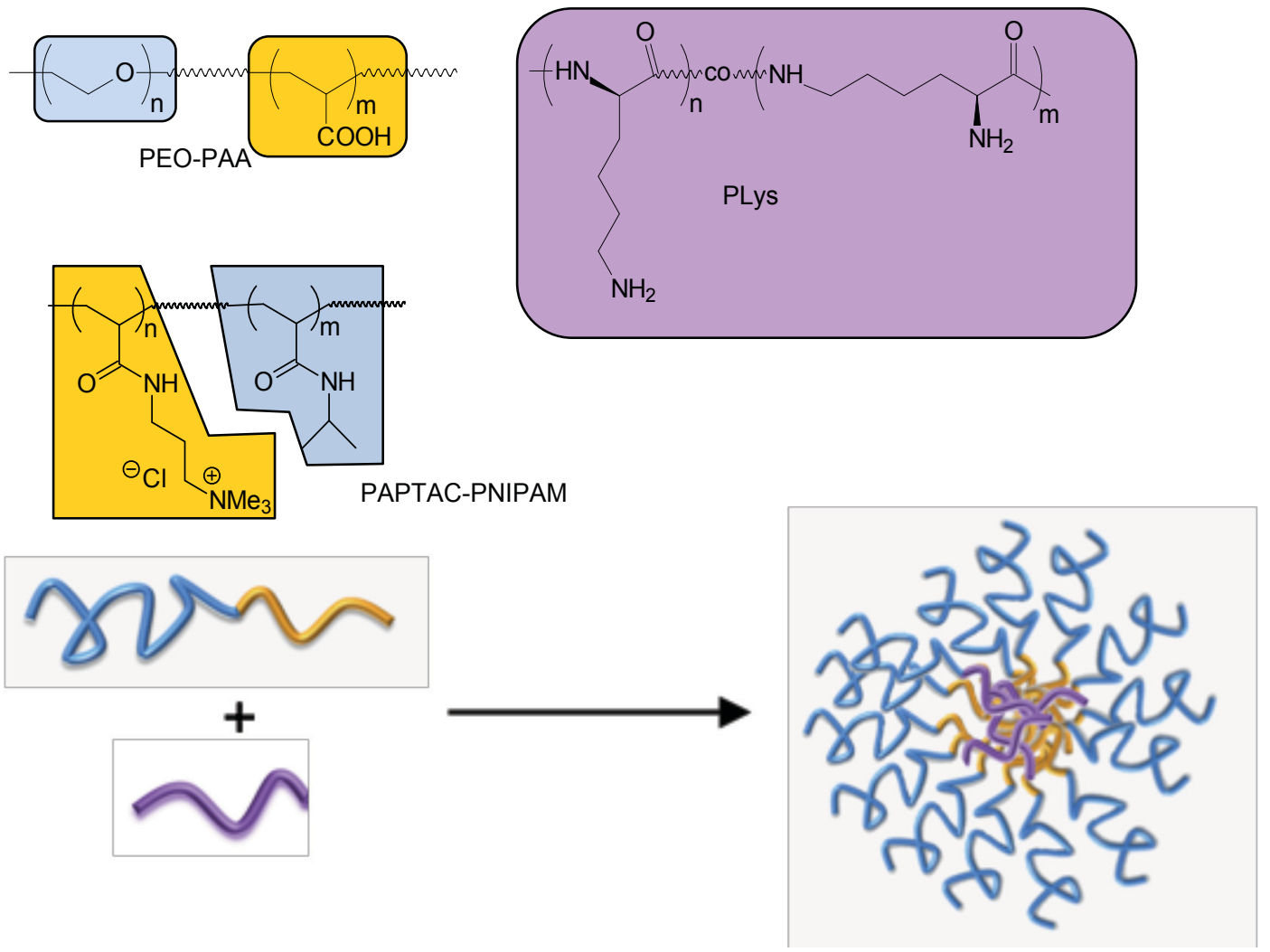

Figure 3. Polymers used for PICs formation

Table 1. Molar masses of the polymer used as controlled by SEC and ${ }^{1} \mathrm{H}$ NMR (table S1)

\begin{tabular}{|c|c|c|}
\hline Name & Mn block 1 $\left(\mathrm{g} \cdot \mathrm{mol}^{-1}\right)$ & Mn block 2 $\left(\mathrm{g} \cdot \mathrm{mol}^{-1}\right)$ \\
\hline PEO-PAA 5-38 & 5000 & 38000 \\
\hline PEO-PAA 6-3 & 6000 & 3000 \\
\hline PEO-PAA 6-6.5 & 6000 & 6500 \\
\hline
\end{tabular}




\begin{tabular}{|c|c|c|}
\hline PEO-PAA 6-12 & 6000 & 12000 \\
\hline PEO-PAA 11-4 & 11000 & 4000 \\
\hline PEO-PAA 28.6-21.1 & 28600 & 21100 \\
\hline PLys & 70000 & \\
\hline DGL3 & 18700 & \\
\hline PAA 10 & 10000 & \\
\hline PAA 1 & 1000 & 9000 \\
\hline PAPTAC-PNIPAM 1-9 & 1000 & 3100 \\
\hline
\end{tabular}

\subsection{DLS characterization}

The formation of assemblies was first confirmed by classical batch DLS (figure 4 and table 2), using data obtained from Malvern instrument followed by fittings by a custom-made software, STORMS, enabling extensive parameter fitting. This software is further described in supplementary information, together with a discussion comparing Malvern to STORMS results. Nano-objects exhibited a size range between $\sim 10$ and $250 \mathrm{~nm}$, ensuring a diversity of objects.

Some of the self-assemblies presented a bimodal population in the intensity relative results as shown in fig. 4, but results in number relative average were all monomodal (fig. S2S6). All polydispersities were in the range 0.1-0.4, indicative of reasonably well defined systems. It is noteworthy that, generally speaking, the estimated PDI in STORMS is larger than the one calculated by the MALVERN software since all the experimental points are selected and the second order equation is used in STORMS instead of the third order for Malvern (see supplementary information). The observed sizes are not linked to the molar masses of the copolymers, but a trend shows that low fractions of the polyelectrolyte block (defined as $\mathrm{M}_{\text {polyelectrolyte block/ }} \mathrm{M}$ copolymer) tend to lead to small PICs, whereas high fractions may yield large objects (figure S7). 

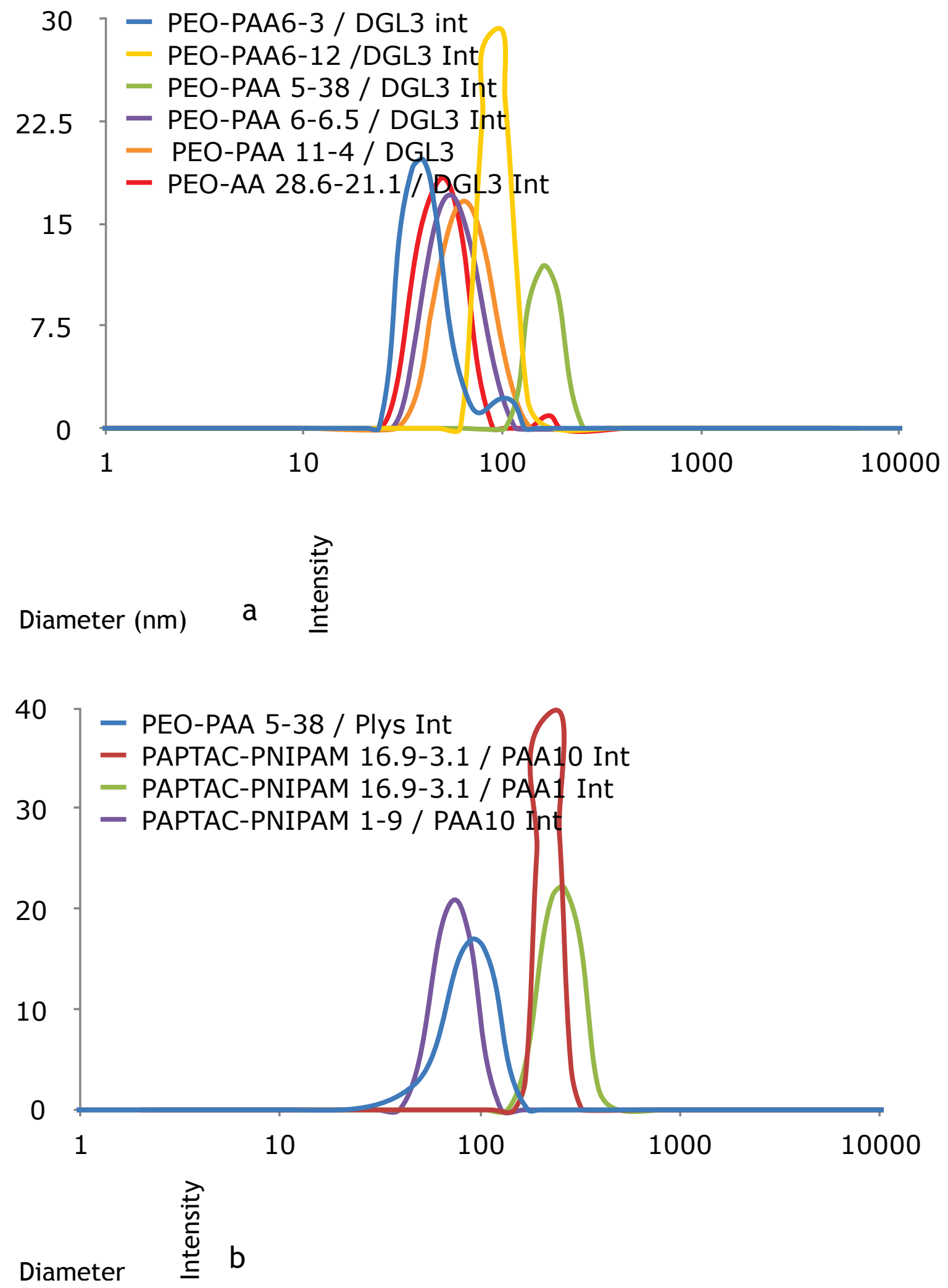

Figure 4: DLS analysis of the different PICs, intensity relative analysis. a: PEO-PAA / DGL3 PICs; b: other PICs 


\begin{tabular}{|c|c|c|c|c|}
\hline PIC & $\begin{array}{l}\text { DLS size int } \\
\quad(\mathrm{nm})\end{array}$ & $\mathrm{PDI}^{\mathrm{a}}{ }_{\text {int }}$ & $\begin{array}{l}\text { DLS size } \\
\text { number }(\mathrm{nm})\end{array}$ & $\mathrm{PDI}^{\mathrm{a}}{ }_{\text {number }}$ \\
\hline $\begin{array}{c}\text { PAPTAC-PNIPAM } \\
\text { 1-9 / PAA } 10\end{array}$ & 75 & 0.2 & 58 & 0.2 \\
\hline $\begin{array}{c}\text { PAPTAC-PNIPAM } \\
\text { 16.9-3.1/PAA10 }\end{array}$ & 222 & 0.1 & 210 & 0.07 \\
\hline $\begin{array}{c}\text { PAPTAC-PNIPAM } \\
\text { 16.9-3.1/PAA } 1\end{array}$ & 252 & 0.21 & 204 & 0.05 \\
\hline $\begin{array}{l}\text { PEO-PAA 6-3 / } \\
\text { DGL3 }\end{array}$ & $42 *$ & 0.39 & 32 & 0.19 \\
\hline $\begin{array}{c}\text { PEO-PAA 6-6.5 / } \\
\text { DGL3 }\end{array}$ & 58 & 0.28 & 42 & 0.21 \\
\hline $\begin{array}{l}\text { PEO-PAA 6-12 / } \\
\text { DGL3 }\end{array}$ & 92 & 0.15 & 86 & 0.1 \\
\hline $\begin{array}{l}\text { PEO-PAA 11-4 / } \\
\text { DGL3 }\end{array}$ & 67 & 0.29 & 45 & 0.23 \\
\hline $\begin{array}{c}\text { PEO-PAA } 28.6-21.1 / \\
\text { DGL3 }\end{array}$ & $50 *$ & 0.33 & 36 & 0.21 \\
\hline $\begin{array}{l}\text { PEO-PAA 5-38 / } \\
\text { DGL3 }\end{array}$ & 166 & 0.2 & 132 & 0.18 \\
\hline PEO-PAA 5-38 / PLys & $90 *$ & 0.3 & 44 & 0.3 \\
\hline
\end{tabular}

Table 2. DLS diameters of PICs. a:polydispersity indices. *bimodal distribution

\subsection{Frit-Inlet FlFFF}

Based on our experience with polymeric self-assemblies [47, 49], some of the formed PICs were first evaluated by AsFIFFF. The obtained fractograms were observed to be erratic (data not shown), in some cases even leading to the absence of peaks after elution. Recovery tests (see supplementary information pS12) showed PICs sensitivity during the essential focus step. The amount of detectable product rapidly decreased during the focus step, even for low flow rates. This phenomenon led us to test the performance of Frit Inlet techniques, to eliminate the stop-flow (FIFFF) and focusing step (AsFlFFF), suspected to be the cause of the PICS degradation observed in conventional AsFlFFF channel.

Recovery tests were first performed using Frit-Inlet Symmetrical Flow FFF for a typical PIC, namely stoichiometric PAPTAC-PNIPAM 1-9/PAA10. The RI peak area was 
recorded for different elution conditions (figure 5). The maximum theoretical area was obtained in the absence of channel and was used as a reference. Adding the channel alone led to a $20 \%$ decrease of the PIC peak area. The addition of crossflow $\mathrm{V}_{\text {cross }}$ did not lead to a further decrease, and a crossflow at $0.6 \mathrm{~mL} \cdot \mathrm{min}^{-1}$ was therefore chosen for all experiments. The injection flow rate was also observed to have no influence on the sample recovery. An injection flow rate at $0.4 \mathrm{~mL} \cdot \mathrm{min}^{-1}$ was therefore chosen. Finally, the flow rate $\mathrm{V}_{\mathrm{f}}$ used in the Frit inlet device was observed to have a strong influence on the recovery of the objects (figure 6). The recovery decreased to $\sim 30 \%$ for $V_{f}=4 \mathrm{~mL} \cdot \mathrm{min}^{-1}$. A higher $\mathrm{V}_{\mathrm{f}}$ did not affect the recovery;. $\mathrm{V}_{\mathrm{f}}$ was thus fixed at $4 \mathrm{~mL} \cdot \mathrm{min}^{-1}$.

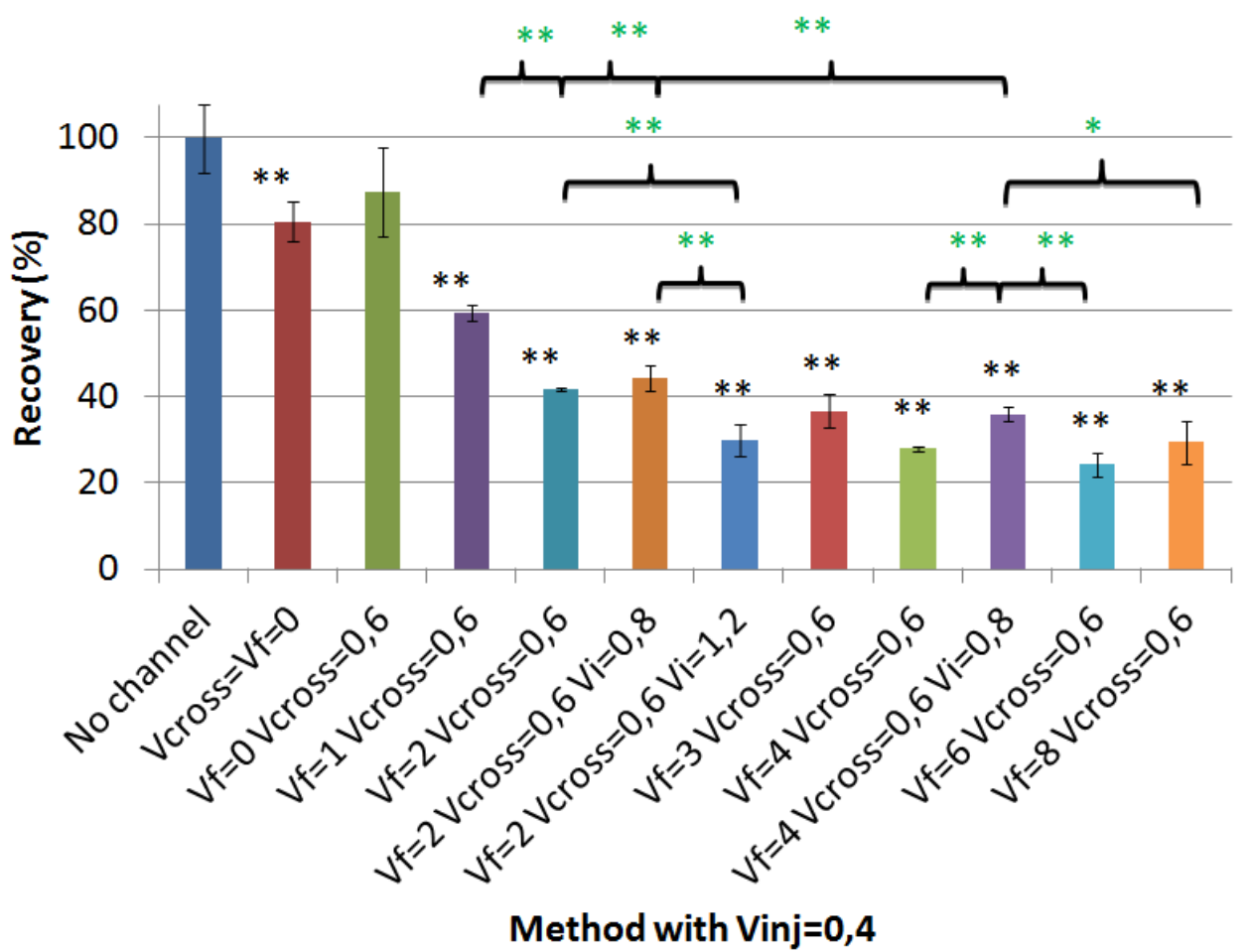




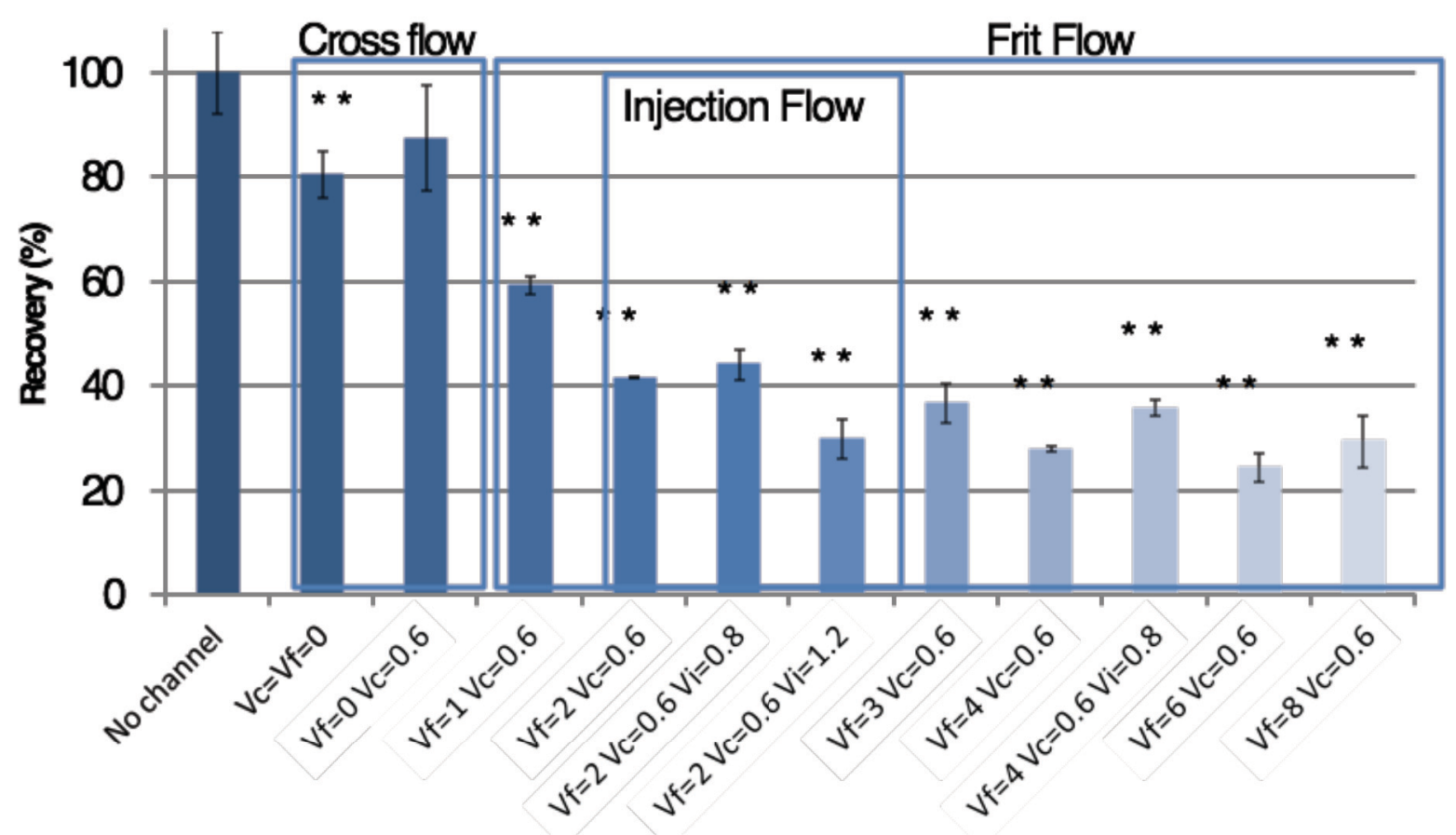

Figure 5: Recovery tests for PAPTAC-PNIPAM 1-9/PAA10. Unless noted, all injections were performed using an injection flow rate $\mathrm{V}_{\mathrm{i}}=0.4 \mathrm{~mL} \cdot \mathrm{min}^{-1}$. All flow rates are given in $\mathrm{mL} \cdot \mathrm{min}^{-1}$. Dunnett's test: $*=\mathrm{p}<0.05$ $* *=\mathrm{p}<0.01$

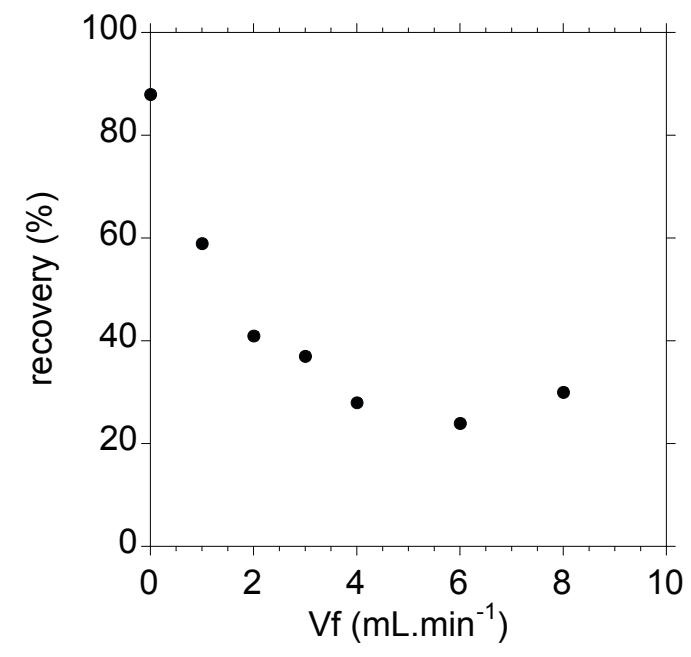

Figure 6 : Recovery of PAPTAC-PNIPAM 1-9 / PAA10 by FI-FIFFF, $\mathrm{V}_{\mathrm{i}}=0.4 \mathrm{~mL} \cdot \mathrm{min}^{-1}$, $\mathrm{V}_{\text {cross }}=0.3 \mathrm{~mL} \cdot \mathrm{min}^{-1}$

In conventional symmetrical FlFFF (SyFlFFF) analyses, a stop flow step is present prior to fractionation where the channel flow is turned off and only the cross flow field is applied to the sample for several minutes[54]. This step allows for analyte relaxation to a steady state equilibrium height near the accumulation wall with smaller analytes positioned higher in the channel on average than larger analytes 
(in the normal mode of FFF). However, it is important to note that the highest sample concentration exists at the semi-permeable membrane accumulation wall[55]. High sample concentrations have been shown to cause sample loss due to irreversible sample adsorption to the membrane[56, 57]. Additionally, if components of the PICs are smaller than the molecular weight cut-off of the semipermeable membrane they can pass through the membrane resulting in lower sample recovery[58]. The use of a frit-inlet flow near the beginning of the channel in addition to constant channel and cross flows eliminates the need for the stop-flow relaxation procedure[31]. This frit-inlet flow rapidly forces analytes towards the accumulation wall allowing for sample relaxation under continuous channel and cross flow conditions. Frit-inlet SyFlFFF (FI-SyFlFFF) can reduce sample loss due to membrane interactions or filtration by avoiding the stop-flow step[59, 60]. The absence of stop-flow during Frit-inlet FIFFF resulted in improved sample recovery for PICs and demonstrated the performance of this method for the PICs analysis. However, the improved sample recoveries are still relatively low (20 to $60 \%$ ). As described by Wahlund, the use of Frit-inlet (FI-AsFlFFF) should increase the performance of this analysis, by improving resolution and giving less sample dilution[61].

PIC PAPTAC-PNIPAM 1-9 / PAA10 was also analyzed by FI-AsFlFFF. As presented in table 3, optimization of $\mathrm{V}_{\mathrm{f}}$ showed that it was possible to obtain higher recoveries in FI-AsFlFFF (up to $77 \%$ ) compared to FI-SyFlFFF $(<60 \%)$. Moreover, this system gives the opportunity to development methods using a $\mathrm{V}_{\text {cross }}$ gradient. Typical recoveries obtained for the different PICs assemblies are reported in table 3, showing that for most systems, very good recoveries were obtained, ensuring trustful analyses of the self-assemblies.

Table 3. FI-AsFIFFF analysis of different PICs $\left(\mathrm{V}_{\text {out }} 1 \mathrm{~mL} \cdot \mathrm{min}^{-1}, \mathrm{~V}_{\mathrm{x}} 2-0.5 \mathrm{~mL} \cdot \mathrm{min}^{-1}, \mathrm{~V}_{\mathrm{i}} 0.2 \mathrm{~mL} \cdot \mathrm{min}^{-1}\right)$

\begin{tabular}{|c|c|c|c|c|c|c|c|c|c|c|c|}
\hline & \multirow[b]{2}{*}{ Polymer 1} & \multirow[b]{2}{*}{$\begin{array}{c}\text { Polymer } \\
2\end{array}$} & \multirow[b]{2}{*}{$\begin{array}{c}\text { Recovery } \\
(\%)\end{array}$} & \multicolumn{4}{|c|}{ Peak 1} & \multicolumn{4}{|c|}{ Peak 2} \\
\hline & & & & $\begin{array}{c}\text { elution } \\
\text { time } \\
\text { (min) }\end{array}$ & $\begin{array}{l}\mathrm{R}_{\mathrm{h}}(\mathrm{n}) \\
(\mathrm{nm})^{\mathrm{a}}\end{array}$ & $\begin{array}{l}\mathrm{R}_{\mathrm{g}}(\mathrm{n}) \\
(\mathrm{nm})^{\mathrm{a}, \mathrm{b}}\end{array}$ & $\mathrm{R}_{\mathrm{g}} / \mathrm{R}_{\mathrm{h}}{ }^{\mathrm{b}}$ & $\begin{array}{c}\text { elution } \\
\text { time } \\
\text { (min) }\end{array}$ & $\begin{array}{l}\mathrm{R}_{\mathrm{h}}(\mathrm{n}) \\
(\mathrm{nm})^{\mathrm{a}}\end{array}$ & $\begin{array}{l}\mathrm{Rg}_{\mathrm{g}}(\mathrm{n}) \\
(\mathrm{nm})^{\mathrm{a}, \mathrm{b}}\end{array}$ & $\mathrm{R}_{\mathrm{g}} / \mathrm{R}_{\mathrm{h}}^{\mathrm{b}}$ \\
\hline A & $\begin{array}{c}\text { PAPTAC- } \\
\text { PNIPAM } \\
1-9\end{array}$ & PAA 10 & 77 & 14 & $50^{\mathrm{b}}$ & $<10^{\mathrm{c}}$ & - & $54 / 66$ & $100 / 200$ & $30 / 40$ & $0.3 / 0.2$ \\
\hline B & DGL3 & $\begin{array}{l}\text { PEO- } \\
\text { PAA 6-3 }\end{array}$ & 99 & 30 & 27 & 17 & 0.62 & & & & \\
\hline $\mathrm{C}$ & DGL3 & $\begin{array}{l}\text { PEO- } \\
\text { PAA } \\
6-6.5\end{array}$ & 100 & 10 & 148 & 64 & 0.43 & 35 & 69 & 36 & 0.52 \\
\hline D & DGL3 & $\begin{array}{c}\text { PEO- } \\
\text { PAA } \\
6-12\end{array}$ & 97 & 25 & 35 & 25 & 0.71 & & & & \\
\hline
\end{tabular}




\begin{tabular}{|c|c|c|c|c|c|c|c|c|c|c|c|}
\hline E & DGL3 & $\begin{array}{c}\text { PEO- } \\
\text { PAA } \\
11-4\end{array}$ & 40 & 9 & 107 & 32 & 0.30 & 35 & 35 & 21 & 0.6 \\
\hline F & DGL3 & $\begin{array}{c}\text { PEO- } \\
\text { PAA } \\
28.6-21 \\
1\end{array}$ & 80 & 12 & 193 & 65 & 0.34 & 28 & 98 & 25 & 0.26 \\
\hline G & DGL3 & $\begin{array}{c}\text { PEO- } \\
\text { PAA } \\
5-38\end{array}$ & 71 & 25 & 38 & 26 & 0.68 & 38 & 53 & 46 & 0.87 \\
\hline
\end{tabular}

a number averaged values. For comparison, table S5 presents the other average types b The used dn/dc (measured or estimated) are presented in supplementary information (table S4). ${ }^{\mathrm{c}}$ inaccuracy $>20 \%$, not trustful value

Fractograms (signal RI and MALS) of PICs for stoichiometric ratios between acidic and basic moieties are presented in figure 7 (A to G). For PICs with PEO-PAA 6-3 and 6-12 (figure 7B and 7D), a residual peak of DGL at 6.5 minutes could be observed and the PIC formation was evidenced by the presence of a major peak eluting around 20-35 minutes. For all other systems (figure 7A, 7C, 7E, 7F and 7G), the PICs were observed as bimodal populations. The corresponding $\mathrm{R}_{\mathrm{h}}$ obtained from DLS and $\mathrm{R}_{\mathrm{g}}$ are also reported in table 3 . If the recovery of all systems was high, the results of the obtained sizes are somewhat surprising. For this size range of nano-objects, normal mode elution is expected and small objects should elute faster than larger ones. Here, it is very surprising that nano-objects of $\mathrm{R}_{\mathrm{h}} \sim 100-200 \mathrm{~nm}$ were observed for elution times as small as 9-10 min, whereas $30-100 \mathrm{~nm}$ PICs eluted after 25 minutes. It is possible that the large analytes eluting at 9-10 min have stronger repulsive interactions with the membrane than the PICs eluting at later times. This earlier than expected elution is possible if the chemical compositions of the two populations are different. Indeed, high adsorption of PEO-PAA copolymers with FFF channel membrane in a salt-free eluent did not permit the analysis of the copolymers (data not shown). It is noteworthy that in the only other published As-FIFFF characterization of a PIC, elution involving both normal and steric processes was observed[52]. In our case, such a dual process could also be considered.

FI-AsFlFFF hyphenated with online MALS and DLS also gave access to the $\mathrm{R}_{\mathrm{g}} / \mathrm{R}_{\mathrm{h}}$ ratio, indicating the morphology of the nano-object. PICs in the literature have been observed to exhibit $\mathrm{R}_{\mathrm{g}} / \mathrm{R}_{\mathrm{h}}$ ratios over a very wide range, from 0.3 to 1.3 , depending on the more or less defined core-shell morphology and the density of the core[3, 7, 8, 62-67]. The values found in this work suggest objects with a dense core for those close to 0.3-0.4 or homogeneous spherical ones for $\mathrm{R}_{\mathrm{g}} / \mathrm{R}_{\mathrm{h}}$ close to $0.7-0.8[18,68]$. Further characterization of the shape and internal structure of the objects, in particular by SAXS, is under way.

Although molecular weights are provided by the program, we decided not to give them, since their determination is based on identified refractive index increments. In the cases presented here, all fractogramms exhibited either a residual DGL peak or several PICs peaks 
indicative of mixtures. In such conditions, the actual composition of each peak cannot be determined.
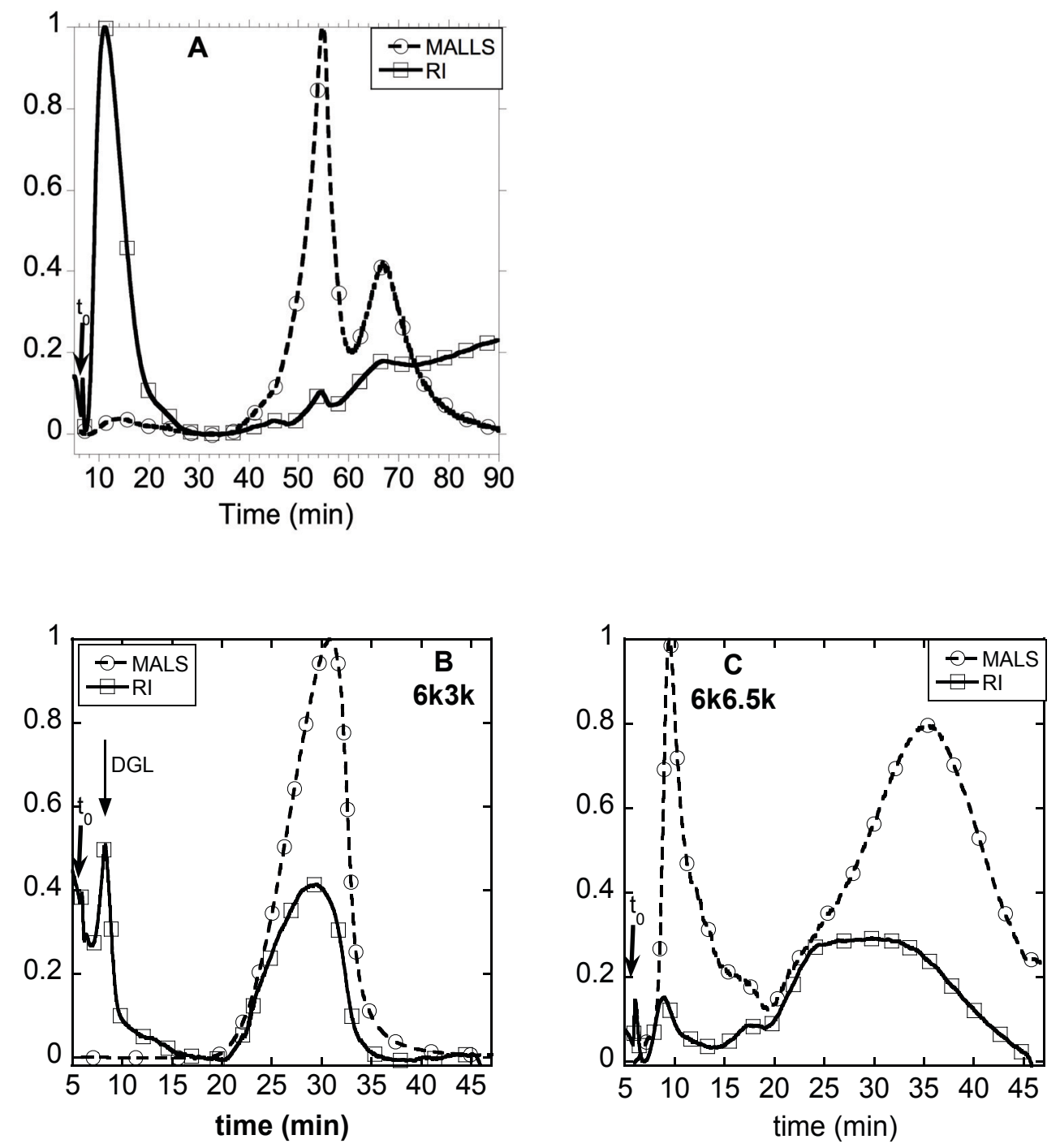

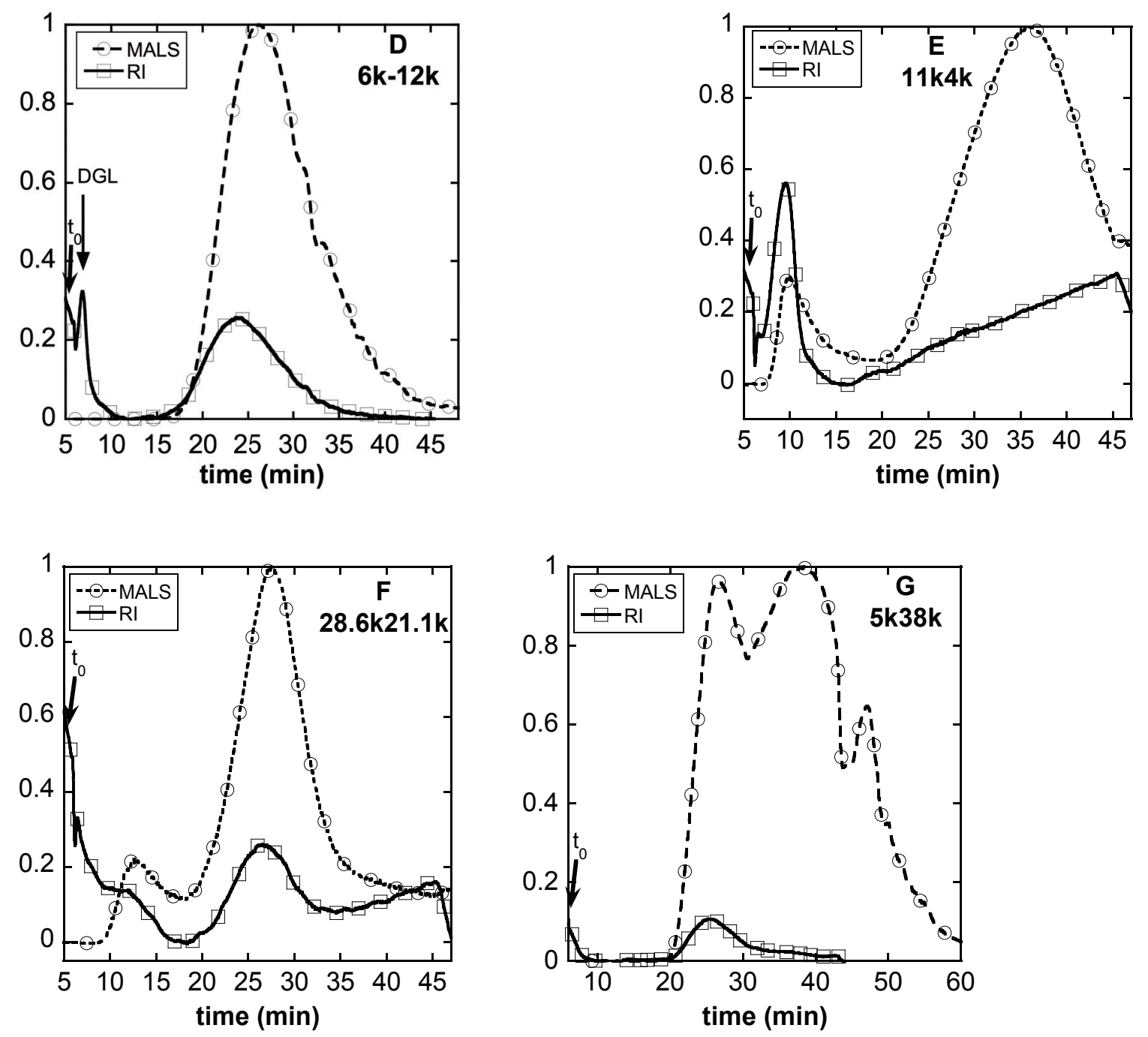

Figure 7 : Frit-Inlet FFF fractograms for PAPTAC-PNIPAM 1-9 / PAA 10 (A) and PEO-PAA / DGL3 PICs. The letter corresponds to the line in table 3. $\mathrm{V}_{\text {out }} 1 \mathrm{~mL} \cdot \mathrm{min}^{-1}, \mathrm{~V}_{\mathrm{x}}$ 2-0.5 mL.min ${ }^{-1}, \mathrm{~V}_{\mathrm{i}} 0.2 \mathrm{~mL} \cdot \mathrm{min}^{-1}$. PICs with PEOPAA 6-12 and 5-38 were eluted with a spacer of 350S, whereas all others were characterized with a $250 \mathrm{~S}$ spacer.

Comparing the results obtained by FFF and batch DLS shows different cases. For PICs based on PEOPAA 6-3 and 11-4 and those of PAPTAC-PNIPAM 1-9 / PAA10, the results are in good agreement for both methods. PICs based on PEO-PAA 6-6.5 and 28.6-21.1 exhibited a much larger size in FFF compared to batch DLS. Finally, those based on PEO-PAA 6-12 and 5-38 presented smaller sizes by FFF compared to batch DLS. At this point, no clear explanation can be provided, although differences in interactions with the FFF membrane could have an influence.

3.4.Additional Studies of PICs stability in the presence of salt 
PEO-PAA / DGL3 PICs were further characterized in the presence of increasing $\mathrm{NaCl}$ concentration. The solutions were analyzed both by batch DLS and FI-AsFIFFF. The results of batch DLS are presented in table 4 and figure 8. Upon addition of $\mathrm{NaCl}$, the scattered light intensity increased for concentrations up to $0.6 \mathrm{M}$ and subsequently severely decreased to near-zero values for concentrations higher than $1.5 \mathrm{M}$. The intensity and number relative sizes increased for low concentrations of salt, a sign of swelling of the self-assembly, followed by their complete dissociation. Above $1 \mathrm{M}$, fitting of the correlograms indicated the presence of several populations of nano-objects, rendering the interpretation difficult (figure S9). The comparison between intensity and number relative diameters showed that very large uncontrolled aggregates were formed in small quantities. This behavior shows that addition of salt severely destabilized the self-assembly, which has been already described in the literature $[6,7]$.

FI-AsFlFFF was used to obtain more information. In order to limit the drawback of FFF analysis in high salt concentration conditions with Vx gradient (drift of RI signal), we decided that all FFF elutions be carried out in pure water. The PICs were prepared in pure water, then exposed to increasingly high concentrations of salt and then eluted by FFF in pure water. Therefore, a difference existed between the analyses by FI-AsFlFFF (samples in $\mathrm{NaCl}$ solutions, but eluted in pure water) and those by batch DLS (samples in $\mathrm{NaCl}$ solutions, analyzed directly). This also implied that during elution, a desalting process took place. This has to be taken into account for the discussion, especially for the highly concentrated solutions for which the sample mainly consisted in soluble polymers whereas desalting might lead to re-assembly during elution (figure 9). In order to assess the rate of re-assembly by desalting, a control experiment was performed, where $\mathrm{NaCl}$ solutions of PEOPAA 6-3 / DGL3 PICs were submitted to dialysis and batch DLS was performed at different times. The results (figure S10 and S11) showed that for low concentrations of salt (0.2M), the PIC self-assembly remained stable. For the high $2 \mathrm{M}$ concentration, desalting led to the formation of uncontrolled self-assembly between 15 and $60 \mathrm{~min}$. This means that samples analyzed by FI-AsFlFFF were subjected to the influence of salt in the initial solution and possibly to the desalting process.

\begin{tabular}{|c|c|c|c|c|c|c|}
\hline$[\mathrm{NaCl}]$ & $\begin{array}{c}\text { DLS size int } \\
(\mathrm{nm})\end{array}$ & $\%$ int & PDI int & $\begin{array}{c}\text { DLS size number } \\
(\mathrm{nm})\end{array}$ & PDI number & $\begin{array}{c}\text { Scattered light } \\
\text { intensity (a.u.) }\end{array}$ \\
\hline 0 & 42 & & 0.39 & 32 & 0.19 & 13500 \\
\hline 0.2 & 72 & 99 & 0.60 & 38 & 0.20 & 25800 \\
\hline 0.6 & 166 & & 0.23 & 124 & 0.20 & 140000 \\
\hline 0.8 & 216 & & 0.20 & 168 & 0.18 & 114800 \\
\hline 1.0 & $1320^{\mathrm{a}}$ & 74 & 2.5 & 228 & 0.48 & 7000 \\
\hline
\end{tabular}




\begin{tabular}{|l|c|c|c|c|c|c|} 
& 300 & 12 & & & & \\
\hline 1.5 & 1040 & 85 & 7.20 & 14 & 0.17 & 1300 \\
& 18 & 13 & & 9 & 0.15 & 1000 \\
\hline 2.0 & 410 & 58 & 1.2 & & & \\
\hline
\end{tabular}

Table 4. Batch DLS characterization of PEO-PAA 6-3 / DGL3 with increasing concentrations of $\mathrm{NaCl} .{ }^{a}$ : presence of very large aggregates $(>1 \mu \mathrm{m})$

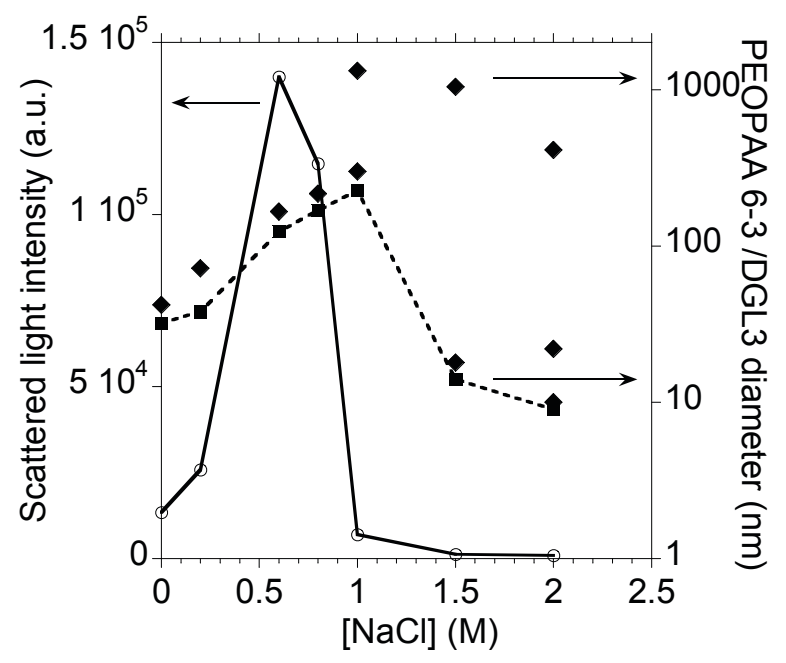

Figure 8: Influence of $\mathrm{NaCl}$ concentration on DLS batch analysis for PEO-PAA 6-3 / DGL3. o: scattered light intensity; $\diamond$ intensity relative diameter; - number relative diameter

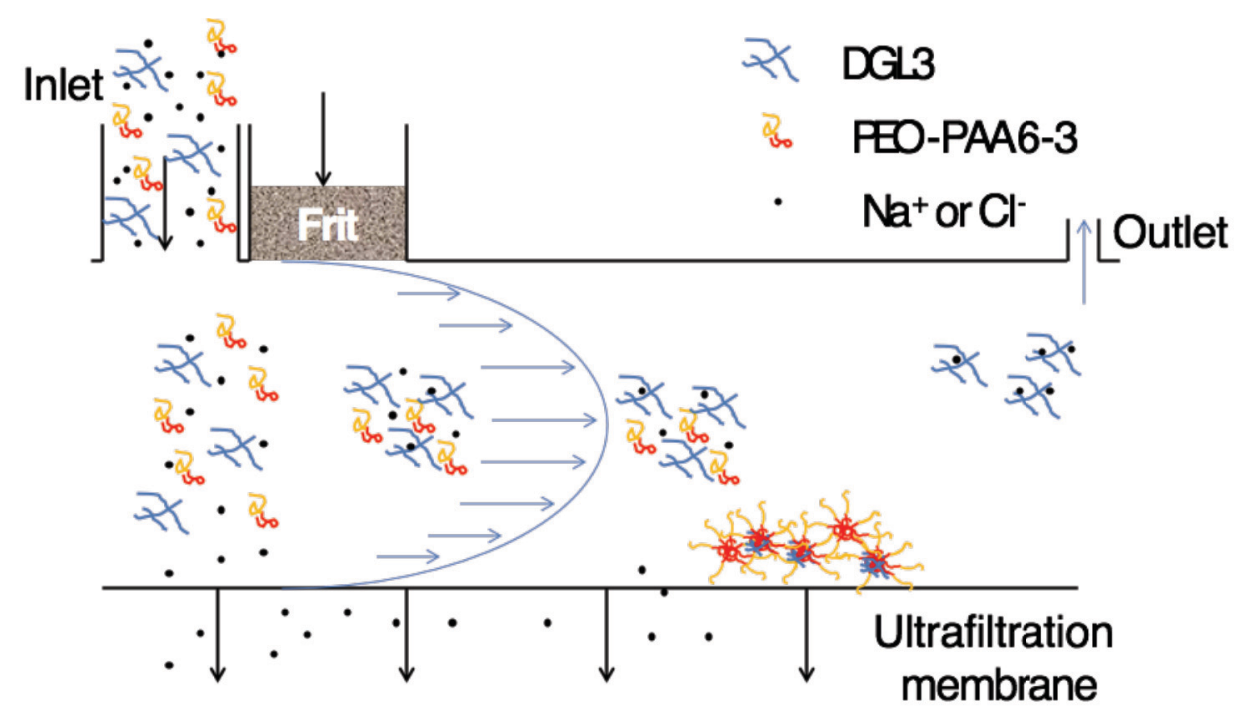

Figure 9: Frit Inlet FFF elution of PEO-PAA 6-3 / DGL3 solutions, in the case of high $\mathrm{NaCl}$ concentration 
The different fractograms are reported in figure 10. Increasing the concentration of salt led to three concomitant processes: increase of the DGL peak at $6.8 \mathrm{~min}$, displacement of the PIC peak for high concentrations of $\mathrm{NaCl}$ and increase of the light scattering signals after 50 minutes of elution. The increase of DGL peak at $6.8 \mathrm{~min}$ is attributed to an ejection of DGL from PIC in the presence of salt. This process was observed for $\mathrm{NaCl}$ concentration of $0.2 \mathrm{M}$, where desalting effect had no influence on the PIC stability. This process can therefore be assumed to occur for all $\mathrm{NaCl}$ concentrations, even in the presence of desalting during elution. Also, from the high intensity of the peak compared to pure DGL, it can be assumed that chloride ions were also associated with DGL. If DGL is ejected from PIC self-assembly, the resulting nano-objects that were analyzed presented therefore a drift in composition from the ideal $1 / 1 \mathrm{acid} /$ amine ratio. Therefore, the radius of gyration of molecular weight of the selfassemblies cannot be determined accurately.

The aggregates that were observed after 50 minutes were released owing to a decrease in the crossflow. Interestingly, although instantaneous DLS correlograms were difficult to interpret, a mean hydrodynamic diameter of $400 \mathrm{~nm}$ was obtained (Table 5), which is close to the size observed by batch DLS in the intensity relative analysis.

The remaining peaks between 20 and 35 minutes were observed to exhibit a size between 50 and $80 \mathrm{~nm}$ for salt concentrations lower than $0.8 \mathrm{M}$, whereas their size was found close to $400 \mathrm{~nm}$ for higher concentrations. It should be noted that analytes with sizes of $\sim 400 \mathrm{~nm}$ could be near the steric transition point where elution switches from normal to steric mode. However, one has to take also into account that, for $2.0 \mathrm{M}$ salt solutions, the desalting process has been shown to lead to re-assembly between 15 and 60 minutes, which corresponds to the elution time in FI-AsFIFFF. One can therefore not reject the possibility that the peaks observed at 25 minutes in this case were in fact self-assemblies produced in the channel during elution.

In the study carried out by Wiedmer[52] on poly(ethylene oxide-b-sodium methacrylate) / poly(methacryloxyethyl trimethylammonium chloride), the resistance of the PIC assembly towards $\mathrm{NaCl}$ was also considered, however at low concentrations between 0.02 and $0.16 \mathrm{M}$. Swelling was observed, in concordance with our work. Cases of bimodal distributions were also observed. In their case, As-FlFFF thus led to good characterization. However, it is noteworthy that the molar mass of their cationic polymer was close to 300000 g.mol-1, which is much higher than the polymers used here. It is therefore possible that this higher molar mass gives a better resistance to focus by the presence of longer chains that can act as anchor in the case of shearing. 

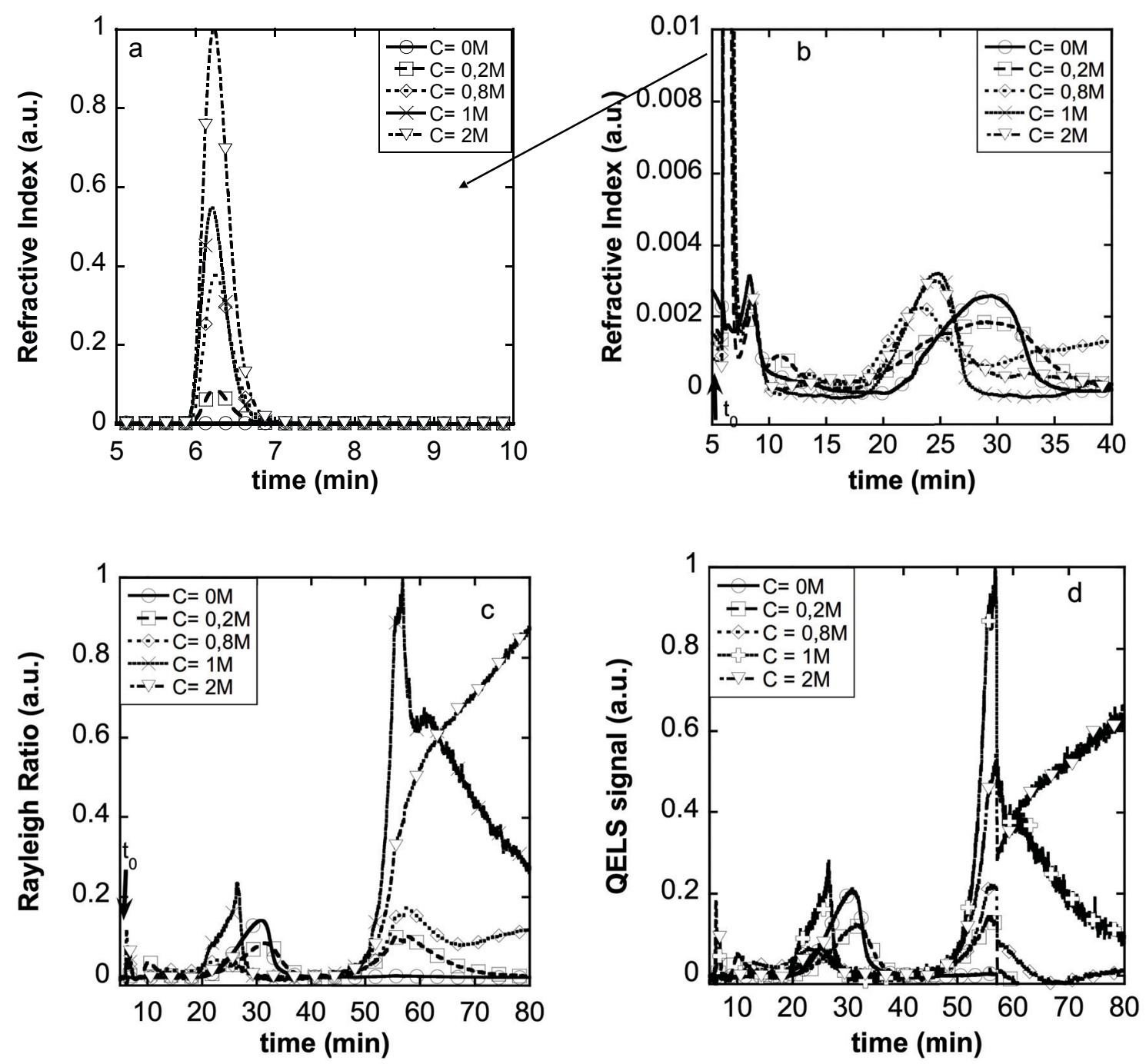

Figure 10: FI-AsFlFFF of PEO-PAA 6-3 / DGL3. a and b: refractive index signal; c: MALS signal; d: DLS signal

\begin{tabular}{|c|c|c|c|c|}
\hline & \multicolumn{2}{|c|}{ Peak 1 } & \multicolumn{2}{c|}{ Peak 2 } \\
\hline$[\mathrm{NaCl}]$ & $\begin{array}{c}\text { elution } \\
\text { time } \\
(\mathrm{min})\end{array}$ & $\begin{array}{c}\mathrm{R}_{\mathrm{h}}(\mathrm{n}) \\
(\mathrm{nm})\end{array}$ & $\begin{array}{c}\text { elution } \\
\text { time } \\
(\mathrm{min})\end{array}$ & $\begin{array}{c}\mathrm{R}_{\mathrm{h}}(\mathrm{n}) \\
(\mathrm{nm})^{\mathrm{a}}\end{array}$ \\
\hline 0 & 28 & 27 & & \\
\hline 0.2 & 28 & 27 & 56 & 100 \\
\hline 0.8 & 23 & 40 & 58 & 80 \\
\hline 1.0 & 24 & “200” & $>50$ & “200” \\
\hline 2.0 & 24 & “200” & $>50$ & “200” \\
\hline
\end{tabular}

Table 5. FI-AsFlFFF analysis of PEO-PAA 6-3 / DGL3 PIC in the presence of NaCl

a number averaged values 


\section{Conclusion}

Polyion complex self-assemblies based on different polymers or copolymers have been formed and analyzed in this work. Batch DLS and FFF characterizations have been crossexamined and have confirmed the strength of FFF when several populations are present. However, it is noteworthy that Frit-Inlet FlFFF was necessary in our case for correct analysis of the PICs, owing to dissociation of the self-assemblies upon focusing with regular AsFlFFF. FI-AsFlFFF also enabled us to characterize the evolution of the self-assemblies in the presence of $\mathrm{NaCl}$ and showed a possible ejection of one of the component from the PIC, leading to a drift in the composition of the PIC's peak in the fractograms. PICs systems are known to be very complex assemblies, owing to their possible dissociation. Their thorough characterization therefore implies the use of multiple techniques to better understand their behavior. Ongoing studies are currently performed in our teams for this, but this work has clearly established FFF as a powerful technique for such characterization.

\section{Acknowledgement}

This work was funded by the Midi-Pyrénées region and University of Toulouse. Mathias Destarac and COLCOM company are acknowledged for kindly providing PAPTAC-bPNIPAM and DGL polymers respectively. Miss Hary Gassama is acknowledged for a short term help. SKRW and CRMB thank the National Science Foundation Grant CHE-1508827 for support.

\section{References}

[1] D.V. Pergushov, A.H.E. Muller, F.H. Schacher, Micellar interpolyelectrolyte complexes, Chemical Society Reviews 41 (2012) 6888-6901.

[2] Y. Lee, K. Kataoka, Biosignal-sensitive polyion complex micelles for the delivery of biopharmaceuticals, Soft Matter 5 (2009) 3810-3817. 
[3] A. Harada, K. Kataoka, Effect of Charged Segment Length on Physicochemical Properties of Core-Shell Type Polyion Complex Micelles from Block Ionomers, Macromolecules 36 (2003) 4995-5001.

[4] P.S. Chelushkin, E.A. Lysenko, T.K. Bronich, A. Eisenberg, V.A. Kabanov, A.V. Kabanov, Polyion Complex Nanomaterials from Block Polyelectrolyte Micelles and Linear Polyelectrolytes of Opposite Charge: 1. Solution Behavior $\dagger$, The Journal of Physical Chemistry B 111 (2007) 8419-8425.

[5] F. Maggi, S. Ciccarelli, M. Diociaiuti, S. Casciardi, G. Masci, Chitosan Nanogels by Template Chemical Cross-Linking in Polyion Complex Micelle Nanoreactors, Biomacromolecules 12 (2011) 3499-3507.

[6] J.-F. Gohy, S.K. Varshney, S. Antoun, R. Jérôme, Water-Soluble Complexes Formed by Sodium Poly(4-styrenesulfonate) and a Poly(2-vinylpyridinium)-blockpoly(ethyleneoxide) Copolymer, Macromolecules 33 (2000) 9298-9305.

[7] S. De Santis, R. Diana Ladogana, M. Diociaiuti, G. Masci, Pegylated and Thermosensitive Polyion Complex Micelles by Self-Assembly of Two Oppositely and Permanently Charged Diblock Copolymers, Macromolecules 43 (2010) 1992-2001.

[8] J. Warnant, N. Marcotte, J. Reboul, G. Layrac, A. Aqil, C. Jerôme, D.A. Lerner, C. Gérardin, Physicochemical properties of $\mathrm{pH}$-controlled polyion complex (PIC) micelles of poly(acrylic acid)-based double hydrophilic block copolymers and various polyamines, Analytical and Bioanalytical Chemistry 403 (2012) 1395-1404.

[9] Y. Kakizawa, A. Harada, K. Kataoka, Environment-Sensitive Stabilization of Core-Shell Structured Polyion Complex Micelle by Reversible Cross-Linking of the Core through Disulfide Bond, Journal of the American Chemical Society 121 (1999) 11247-11248.

[10] S. Herlambang, M. Kumagai, T. Nomoto, S. Horie, S. Fukushima, M. Oba, K. Miyazaki, Y. Morimoto, N. Nishiyama, K. Kataoka, Disulfide crosslinked polyion complex micelles encapsulating dendrimer phthalocyanine directed to improved efficiency of photodynamic therapy, Journal of Controlled Release 155 (2011) 449-457.

[11] J. Wang, D. Zhao, Y. Wang, G. Wu, Imine bond cross-linked poly(ethylene glycol)block-poly(aspartamide) complex micelle as a carrier to deliver anticancer drugs, RSC Advances 4 (2014) 11244-11250.

[12] J. Zhang, Y. Zhou, Z. Zhu, Z. Ge, S. Liu, Polyion Complex Micelles Possessing Thermoresponsive Coronas and Their Covalent Core Stabilization via "Click" Chemistry, Macromolecules 41 (2008) 1444-1454.

[13] R. Ideta, F. Tasaka, W.-D. Jang, N. Nishiyama, G.-D. Zhang, A. Harada, Y. Yanagi, Y. Tamaki, T. Aida, K. Kataoka, Nanotechnology-Based Photodynamic Therapy for Neovascular Disease Using a Supramolecular Nanocarrier Loaded with a Dendritic Photosensitizer, Nano Letters 5 (2005) 2426-2431.

[14] W.-D. Jang, N. Nishiyama, D. Zhang, A. Harada, D.-L. Jiang, S. Kawauchi, Y. Morimoto, M. Kikuchi, H. Koyama, T. Aida, K. Kataoka, Supramolecular nanocarrier of anionic dendrimer porphyrins with cationic block copolymers modified with polyethyleneglycol to enhance intracellular photodynamic efficacy, Angewandte Chemie, International Edition in English 44 (2005) 419-423.

[15] W.-D. Jang, Y. Nakagishi, N. Nishiyama, S. Kawauchi, Y. Morimoto, M. Kikuchi, K. Kataoka, Polyion complex micelles for potodynamic therapy: incorporation of 
dendritic photosensitizer excitable at long wavelength relevant to improved tissuepenetrating property, Journal of Controlled Release 113 (2006) 73-79.

[16] H. Chen, L. Xiao, Y. Anraku, P. Mi, X. Liu, H. Cabral, A. Inoue, T. Nomoto, A. Kishimura, N. Nishiyama, K. Kataoka, Polyion Complex Vesicles for Photoinduced Intracellular Delivery of Amphiphilic Photosensitizer, Journal of the American Chemical Society 136 (2014) 157-163.

[17] M. Dionzou, A. Morère, C. Roux, B. Lonetti, J.-D. Marty, C. Mingotaud, P. Joseph, D. Goudounèche, B. Payré, M. Léonetti, A.F. Mingotaud, Comparison of methods for the fabrication and the characterization of polymer self-assemblies: what are the important parameters? , Soft Matter 12 (2016) 2166-2176.

[18] J.P. Patterson, M.P. Robin, C. Chassenieux, O. Colombani, R.K. O'Reilly, The analysis of solution self-assembled polymeric nanomaterials, Chemical Society Reviews 43 (2014) 2412-2425.

[19] A. Zattoni, B. Roda, F. Borghi, V. Marassi, P. Reschiglian, Flow field flow fractionation for the analysis of nanoparticles used in drug delivery, Journal of Pharmaceutical and Biomedical Analysis 87 (2014) 53-61.

[20] C. Bria, F. Violleau, S.K.R. Williams, Field-Flow Fractionation for Biological, Natural, and Synthetic Polymers: Recent advances and trends, Lc Gc Asia Pacific 16 (2013) 8-16.

[21] L. Nilsson, Separation and characterization of food macromolecules using field-flow fractionation: A review, Food Hydrocolloids 30 (2013) 1-11.

[22] F. von der Kammer, S. Legros, E.H. Larsen, K. Loeschner, T. Hofmann, Separation and characterization of nanoparticles in complex food and environmental samples by field-flow fractionation, Trends in Analytical Chemistry 30 (2011) 425-436.

[23] M. Baalousha, B. Stolpe, J.R. Lead, Flow field-flow fractionation for the analysis and characterization of natural colloids and manufactured nanoparticles in environmental systems: A critical review, Journal of Chromatography A 1218 (2011) 4078-4103.

[24] G. Yohannes, M. Jussila, K. Hartonen, M.L. Riekkola, Asymmetrical flow field-flow fractionation technique for separation and characterization of biopolymers and bioparticles, Journal of Chromatography A 1218 (2011) 4104-4116.

[25] R.N. Qureshi, W.T. Kok, Application of flow field-flow fractionation for the characterization of macromolecules of biological interest: a review, Analytical and Bioanalytical Chemistry 399 (2011) 1401-1411.

[26] D.C. Rambaldi, P. Reschiglian, A. Zattoni, Flow field-flow fractionation: recent trends in protein analysis, Analytical and Bioanalytical Chemistry 399 (2011) 1439-1447.

[27] B. Roda, A. Zattoni, P. Reschiglian, M.H. Moon, M. Mirasoli, E. Michelini, A. Roda, Field-flow fractionation in bioanalysis: A review of recent trends, Analytica Chimica Acta 635 (2009) 132-143.

[28] P. Reschiglian, M.H. Moon, Flow field-flow fractionation: A pre-analytical method for proteomics, journal of proteomics 71 (2008) 265-276.

[29] W. Fraunhofer, G. Winter, The use of asymmetrical flow field-flow fractionation in pharmaceutics and biopharmaceutics, European Journal of Pharmaceutics and Biopharmaceutics 58 (2004) 369-383.

[30] M.-K. Liu, P.S. Williams, M.N. Myers, J.C. Giddings, Hydrodynamic Relaxation in Flow Field-Flow Fractionation Using Both Split and Frit Inlets, Analytical Chemistry 63 (1991) 2115-2122. 
[31] J.C. Giddings, Hydrodynamic relaxation and sample concentration in field-flow fractionation using permeable wall elements, Analytical Chemistry 62 (1990) 2306-2312.

[32] M.-K. Liu, P. Li, J.C. Giddings, Rapid protein separation and diffusion coefficient measurement by frit inlet flow field-flow fractionation, Protein Sciences 2 (1993) 1520-1531.

[33] M.H. Moon, Frit-Inlet Asymmetrical Flow Field-Flow Fractionation : A Stopless Separation Technique for the Separation of Macromolecules and Nanoparticles, Bulletin of the Korean Chemical Society 22 (2001) 337-348.

[34] M.H. Moon, P.S. Williams, H. Kwon, Retention and Efficiency in Frit Inlet Asymmetrical Flow Field-Flow Fractionation (FIA-FlFFF), Analytical Chemistry 71 (1999) 2957-2666.

[35] M.H. Moon, H. Kwon, I. Park, Stopless Flow Injection in Asymmetrical Flow FieldFlow Fractionation Using a Frit Inlet, Analytical Chemistry 69 (1997) 1436-1440.

[36] M.H. Moon, H. Kwon, I. Park, Stopless Separation of Proteins by Frit-Inlet Asymmetrical Flow Field-Flow Fractionation, Journal of liquid chromatography and related technologies 20 (1997) 2803-2814.

[37] M.H. Moon, J. Lee, J. Park, Effect of Inlet Frit Lengths in the Hydrodynamic Relaxation Efficiency in Frit Inlet Asymmetrical Flow Field Flow Fractionation, Journal of liquid chromatography and related technologies 26 (2003) 2369-2379.

[38] D. Kang, M.H. Moon, Miniaturization of Frit Inlet Asymmetrical Flow Field-Flow Fractionation, Analytical Chemistry 76 (2004).

[39] M.H. Moon, D. Kang, I. Hwang, P.S. Williams, Field and Flow Programming in FritInlet Asymmetrical Flow Field-Flow Fractionation, Journal of Chromatography A 955 (2002) 263-272.

[40] I. Park, K.-J. Paeng, Y. Yoon, J.-H. Song, M.H. Moon, Separation and Selective Detection of Lipoprotein Particles of Patients with Coronary Artery Disease by FritInlet Asymmetrical Flow Field-Flow Fractionation, Journal of Chromatography B 780 (2002) 415-422.

[41] M.H. Moon, D. Kang, K. Jung, J. Kim, Separation of Carbon Nanotubes by Frit Inlet Asymmetrical Field-Flow Fractionation, Journal of Separation Science 27 (2004) 710-717.

[42] H. Lee, H. Kim, M.H. Moon, Field Programming in Frit Inlet Asymmetrical Flow Field-Flow Fractionation/Multiangle Light Scattering: Application to Sodium Hyaluronate, Journal of Chromatography A 1089 (2005) 203-210.

[43] H. Kim, H. Lee, M.H. Moon, Size Characterization of Sodium Hyaluronate by Field Programming Frit Inlet Asymmetrical Flow Field-Flow Fractionation/Multiangle Light Scattering, Bulletin of the Korean Chemical Society 27 (2006) 413-418.

[44] M. Ali, E. Hwang, I.-H. Cho, M.H. Moon, Characterization of Sodium Hyaluronate Blends Using Frit Inlet Asymmetrical Flow Field-Flow Fractionation \& Multiangle Light Scattering, Analytical and Bioanalytical Chemistry 402 (2012) 1269-1276.

[45] S. Woo, J.W. Lee, W. Choi, M.H. Moon, Characterization of Ultrahigh Molecular Weight Cationic Polyacrylamide by Frit-Inlet Asymmetrical Flow Field-Flow Fractionation and Multiangle Lightscattering, Journal of Chromatography A 1429 (2016) 304-310. 
[46] K. Knop, A.F. Mingotaud, N. El-Akra, F. Violleau, J.P. Souchard, Monomeric pheophorbide(a)-containing poly(ethyleneglycol-b-epsilon-caprolactone) micelles for photodynamic therapy, Photochem Photobiol Sci 8 (2009) 396-404.

[47] J. Ehrhart, A.-F. Mingotaud, F. Violleau, Asymmetrical flow field-flow fractionation with multi-angle light scattering and quasi elastic light scattering for characterization of poly(ethyleneglycol-b-e-caprolactone) block copolymer self-assemblies used as drug carriers for photodynamic therapy, Journal of Chromatography A 1218 (2011) 4249-4256.

[48] L. Gibot, A. Lemelle, U. Till, B. Moukarzel, A.F. Mingotaud, V. Pimienta, P. SaintAguet, M.P. Rols, M. Gaucher, F. Violleau, C. Chassenieux, P. Vicendo, Polymeric micelles encapsulating photosensitizer: structure/ photodynamic therapy efficiency relation, Biomacromolecules 15 (2014) 1443-1455.

[49] U. Till, M. Gaucher-Delmas, P. Saint-Aguet, G. Hamon, J.-D. Marty, C. Chassenieux, B. Payré, D. Goudounèche, A.F. Mingotaud, F. Violleau, Asymmetrical Flow FieldFlow Fractionation with Multi-Angle Light Scattering and Quasi Elastic Light Scattering for characterization of polymersomes: comparison with classical techniques, Analytical and Bioanalytical Chemistry 406 (2014) 7841-7853.

[50] D. Le Cerf, S. Simon, J.-F. Argillier, L. Picton, Contribution of flow field flow fractionation with on line static and dynamic light scattering to the study of hydrosoluble polyelectrolyte complexes, Analytica Chimica Acta 604 (2007) 2-8.

[51] D. Le Cerf, A.S. Pepin, P.M. Niang, M. Cristea, C. Karakasyan-Dia, L. Picton, Formation of polyelectrolyte complexes with diethylaminoethyl dextran: Charge ratio and molar mass effect, Carbohydrate Polymers 113 (2014) 217-224.

[52] G. Yohannes, S. Holappa, S.K. Wiedmer, T. Andersson, H. Tenhu, M.-L. Riekkola, Polyelectrolyte complexes of poly(methacryloxyethyl trimethylammonium chloride) and poly(ethylene oxide)-block-poly(sodium methacrylate) studied by asymmetrical flow field-flow fractionation and dynamic light scattering, Analytica Chimica Acta 542 (2005) 222-229.

[53] A.T. Sutton, E. Read, A.R. Maniego, J.J. Thevarajah, J.-D. Marty, M. Destarac, M. Gaborieau, P. Castignolles, Purity of double hydrophilic block copolymers revealed by capillaryelectrophoresis in the critical conditions, Journal of Chromatography A 1372 (2014) 187-195.

[54] K.G. Wahlund, Flow field-flow fractionation : Critical overview, Journal of Chromatography A 1287 (2013) 97-112.

[55] M. Schimpf, K. Caldwell, J.C. Giddings, Field-Flow Fractionation Handbook, John Wiley \& Sons (New York), 2000.

[56] R.L. Hartmann, S.K.R. Williams, Flow field-flow fractionation as an analytical technique to rapidly quantitate membrane fouling, Journal of Membrane Science 209 (2002) 93-106.

[57] G.E. Kassalainen, S.K.R. Williams, Assessing protein-ultrafiltration membrane interactions using flow field-flow fractionation, in: S.K.R. Williams, K. Caldwell, (Eds.), Field-Flow Fractionation Biopolym. Anal., Springer-Verlag, Wien, 2012.

[58] J. Ashby, S. Schachermeyer, Y. Duan, L.A. Jimenez, W. Zhong, Probing and quantifying DNA-protein interactions with asymmetrical flow field-flow fractionation, Journal of Chromatography A 1358 (2014) 217-224. 
[59] P. Li, M. Hansen, J.C. Giddings, Advances in frit-inlet and frit-outlet flow field-flow fractionation, Journal of Microcolumn Separation 10 (1998) 7-18.

[60] M.H. Moon, I. Hwang, Hydrodynamic vs. focusing relaxation in asymmetrical flow field-flow fractionation, Journal of Liquid Chromatography and Related Technologies 24 (2001) 3069-3083.

[61] A. Litzen, K.G. Wahlund, Zone broadening and dilution in rectangular and trapezoidal asymmetrical flow field-flow fractionation channels, Analytical Chemistry 63 (1991) 1001-1007.

[62] J. Li, W.-D. He, N. He, S.-C. Han, X.-L. Sun, L.-Y. Li, B.-Y. Zhang, Synthesis of PEG-PNIPAM-PLys hetero-arm star polymer and its variation of thermoresponsibility after the formation of polyelectrolyte complex micelles with PAA, Journal of Polymer Science Part A: Polymer Chemistry 47 (2009) 1450-1462.

[63] A. Harada, K. Kataoka, Novel Polyion Complex Micelles Entrapping Enzyme Molecules in the Core. 2. Characterization of the Micelles Prepared at Nonstoichiometric Mixing Ratios, Langmuir 15 (1999) 4208-4212.

[64] A. Harada, K. Kataoka, Novel Polyion Complex Micelles Entrapping Enzyme Molecules in the Core: Preparation of Narrowly-Distributed Micelles from Lysozyme and Poly(ethylene glycol)-Poly(aspartic acid) Block Copolymer in Aqueous Medium, Macromolecules 31 (1998) 288-294.

[65] A. Harada, K. Kataoka, Switching by Pulse Electric Field of the Elevated Enzymatic Reaction in the Core of Polyion Complex Micelles, Journal of the American Chemical Society 125 (2003) 15306-15307.

[66] R. Ma, B. Wang, X. Liu, Y. An, Y. Li, Z. He, L. Shi, Pyranine-Induced Micellization of Poly(ethylene glycol)-block-poly(4-vinylpyridine) and pH-Triggered Release of Pyranine from the Complex Micelles, Langmuir 23 (2007) 7498-7504.

[67] S.-i. Yusa, Y. Yokoyama, Y. Morishima, Synthesis of Oppositely Charged Block Copolymers of Poly(ethylene glycol) via Reversible Addition-Fragmentation Chain Transfer Radical Polymerization and Characterization of Their Polyion Complex Micelles in Water, Macromolecules 42 (2009) 376-383.

[68] W. Burchard, Static and dynamic light scattering from branched polymers and biopolymers, Light Scattering from Polymers, Springer Berlin Heidelberg, Berlin, Heidelberg, 1983, pp. 1-124. 


\section{Figure Captions}

Figure 1. Experimental set-up for Symmetrical FFF

Figure 2. Experimental set-up for Asymmetrical FFF

Figure 3. Polymers used for PICs formation

Table 1. Molar masses of the polymer used as controlled by SEC and ${ }^{1} \mathrm{H}$ NMR (table S1)

Figure 4: DLS analysis of the different PICs, intensity relative analysis. a: PEO-PAA / DGL3 PICs; b: other PICs

Table 2. DLS diameters of PICs. a:polydispersity indices

Figure 5: Recovery tests for PAPTAC-PNIPAM 1-9/PAA10. Unless noted, all injections were performed using an injection flow rate $\mathrm{V}_{\mathrm{i}}=0.4 \mathrm{~mL} \cdot \mathrm{min}^{-1}$. Dunnett's test: $*=\mathrm{p}<0.05$ $* *=\mathrm{p}<0.01$

Figure 6 : Recovery of PAPTAC-PNIPAM 1-9 / PAA10 by FI-FIFFF, Vi $=0.4$ mL.min ${ }^{-1}$, $\mathrm{V}_{\text {cross }}=0.3 \mathrm{~mL} \cdot \mathrm{min}^{-1}$

Table 3. FI-AsFlFFF analysis of different PICs $\left(\mathrm{V}_{\text {out }} 1 \mathrm{~mL} \cdot \mathrm{min}^{-1}, \mathrm{~V}_{\mathrm{x}} 2-0.5 \mathrm{~mL} \cdot \mathrm{min}^{-1}, \mathrm{~V}_{\mathrm{i}} 0.2\right.$ $\left.\mathrm{mL} \cdot \mathrm{min}^{-1}\right)$

Figure 7 : Frit-Inlet FFF fractograms for PAPTAC-PNIPAM 1-9 / PAA 10 (A) and PEOPAA / DGL3 PICs. The letter corresponds to the line in table 3. $\mathrm{V}_{\text {out }} 1 \mathrm{~mL}^{\mathrm{min}}{ }^{-1}, \mathrm{~V}_{\mathrm{x}} 2-0.5$ mL.min ${ }^{-1}, V_{i} 0.2$ mL.min ${ }^{-1}$. PICs with PEOPAA 6-12 and 5-38 were eluted with a spacer of $350 \mathrm{~S}$, whereas all others were characterized with a $250 \mathrm{~S}$ spacer.

Table 4. Batch DLS characterization of PEO-PAA 6-3 / DGL3 with increasing concentrations of $\mathrm{NaCl} .{ }^{\mathrm{a}}$ : presence of very large aggregates $(>1 \mu \mathrm{m})$

Figure 8: Influence of $\mathrm{NaCl}$ concentration on DLS batch analysis for PEO-PAA 6-3 / DGL3. $\mathrm{o}$ : scattered light intensity; $\bullet$ intensity relative diameter; $\mathbf{~ n u m b e r ~ r e l a t i v e ~ d i a m e t e r ~}$ Figure 9: Frit Inlet FFF elution of PEO-PAA 6-3 / DGL3 solutions, in the case of high $\mathrm{NaCl}$ concentration

Figure 10: FI-AsFlFFF of PEO-PAA 6-3 / DGL3. a and b: refractive index signal; c: MALS signal; d: DLS signal

Table 5. FI-AsFlFFF analysis of PEO-PAA 6-3 / DGL3 PIC in the presence of $\mathrm{NaCl}$ 